\title{
Beneficial and Detrimental Effects of Soil-Structure Interaction on Probabilistic Seismic Hazard and Risk of Nuclear Power Plant
}

\author{
Shinyoung Kwag, ${ }^{1}$ BuSeog Ju $\mathbb{D}^{2},{ }^{2}$ and Wooyoung Jung $\mathbb{D}^{3}$ \\ ${ }^{1}$ Korea Atomic Energy Research Institute, Daejeon, Republic of Korea \\ ${ }^{2}$ Department of Civil Engineering, Kyung Hee University, Yongin, Gyeonggi 17104, Republic of Korea \\ ${ }^{3}$ Department of Civil Engineering, Gangneung-Wonju National University, Gangneung, Republic of Korea \\ Correspondence should be addressed to BuSeog Ju; bju2@khu.ac.kr
}

Received 9 April 2018; Revised 14 May 2018; Accepted 4 June 2018; Published 3 July 2018

Academic Editor: Lars Abrahamczyk

Copyright (c) 2018 Shinyoung Kwag et al. This is an open access article distributed under the Creative Commons Attribution License, which permits unrestricted use, distribution, and reproduction in any medium, provided the original work is properly cited.

\begin{abstract}
The purpose of this study is to investigate the soil-structure interaction (SSI) effect on the overall risk of a PWR containment building structure with respect to two failure modes: strength and displacement. The precise quantification of the risk within the seismic probabilistic risk assessment framework depends considerably on an accurate treatment of the seismic response analysis. The SSI effect is one of the critical factors to consider when accurately predicting structural responses in the event of an earthquake. Previous studies have been conducted by focusing more on the positive side of the SSI effects and the effects mainly on the seismic fragility result. Therefore, this paper presents the results of a study of the SSI effect on the overall risk. Also, the study relies on an emphasis on revealing a beneficial and a detrimental effect of the SSI by utilizing an example of the containment structure in three soil conditions and two main failure modes. As a result, the consideration of SSI shows a complete conflicting effect on the seismic fragility and risk results depending on two failure modes considered in this study. This has a positive effect regarding the strength failure mode, but this brings a negative effect regarding the displacement failure mode. The risk fluctuation width is particularly noticeable in the site having a considerable change in seismic hazard information such as Los Angeles on the western site of the US. Such results can be expected to be utilized in a future study for investigating the pros and cons of the SSI effect associated with various failure modes in diverse conditions.
\end{abstract}

\section{Introduction}

Historically, strong earthquakes are not uncommon near the current sites of nuclear power plants. Examples include but are not limited to the 1811-1812 New Madrid earthquake, the 1886 Charleston earthquake, and the 1994 Northridge earthquake in the US. The 2011 Tohoku earthquake occurred in Japan, and the subsequent accident at the Fukushima Daiichi nuclear power plants demonstrated the need to explore scenarios in which the possible seismic hazard exceeds the design basis earthquake levels. Accordingly, this accident has motivated nuclear regulatory organizations to reassess the safety of nuclear facilities and evaluate the seismic margins and risk levels of such facilities in the US, EU, and Korea [1-3]. Such a situation once again sheds new light on the importance of seismic margin assessment (SMA) $[4,5]$ and seismic probabilistic risk assessment (SPRA) [6-9] practices after the individual plant examination of external events (IPEEE) for severe accidents [10]. The SMA is intended to estimate how much margin exists at a plant above a design basis earthquake event based on the seismic fragility information of major systems, structures, and components. The SPRA is a more complete framework than the SMA because it integrates the seismic fragility data and seismic hazard information. One factor in common regarding the two methodologies is that they rely fundamentally on an accurate seismic response analysis as part of a fragility evaluation [11].

The seismic responses of structures, as the basic seismic fragility analysis data, are greatly affected not only by the 
dynamic characteristics of the structures but also by the supporting soil stratum. The seismic responses accounting for the supporting soil deposits form the end result of the earthquake source, the travel path effects, the local site effects, and the soil-structure interaction (SSI) effect [12]. The result of the first three of these factors is the free-field ground motion. The structural responses with regard to the free-field motion are influenced by the SSI effect. Thus, an accurate assessment of the seismic performance of a structure requires the appropriate estimation of the free-field motion acting on the foundation of the structure and a proper consideration of the SSI effect. There remains controversy regarding the role of SSI in the seismic performance of structures embedded in soft soil. Traditionally, taking into account the SSI effect has been considered as a beneficial factor in the seismic response [13]. The beneficial effect emerges with reductions in the internal force and drift in the structure as the soft soil in the entire soil-structure system causes an increased structural period owing to its flexibility and plays a significant role in amplifying the energy dissipation effect in the response.

However, the reality occasionally differs from the positive perspective of the SSI effect. It should be considered that the SSI can have a detrimental effect on a flexible secondary system attached to the primary soil-structure system because it filters out high-frequency contents but amplifies the lowfrequency contents of motions in the secondary system. In addition, because the soft soil at the bottom of the structure serves as a flexible pad, it can bring about excessive displacement in the structure. This phenomenon has a negative impact on closely connected structures, for example, a nuclear power plant, by causing adjacent structures consisting of the nuclear power plant to crash into one another. In this context, the USNRC has increased the soil-condition acceptance criterion which can neglect the SSI effect. For structures founded on soils having a shear-wave velocity in a range between $1,070 \mathrm{~m} / \mathrm{s}$ and $2,440 \mathrm{~m} / \mathrm{s}$ under the entire surface of the foundation, a fixed-base assumption cannot be acceptable to the regulatory body, any more. This is because the USNRC modified such a limit criterion from $1,070 \mathrm{~m} / \mathrm{s}$ to $2,440 \mathrm{~m} / \mathrm{s}$ in the Standard Review Plan (SRP) 3.7.2. This indicates that the structure having the soil which has less than $2,440 \mathrm{~m} / \mathrm{s}$ of shear-wave velocity cannot be regarded as a model supported in the fixed-base condition. This enhanced criterion is a result reflecting the outcome of current research works in which the soil originally considered as relatively stiff (i.e., $1,070 \mathrm{~m} / \mathrm{s}-2,440 \mathrm{~m} / \mathrm{s}$ ) can possibly influence the structure responses, quite a lot [14].

The research exploring the SSI effects on the responses and probabilistic seismic vulnerabilities of the structure has been actively studied recently [15-17]. Especially, such studies were subsequently extended into such SSI studies on nuclear power plants (NPPs). The common features of these current studies have focused on the NPP containment building structure and attempted to associate the SSI effect with a seismic fragility analysis of the NPP [18, 19]. In addition, these studies were restricted to the positive effects of the SSI and focused on the SSI effect only on the seismic fragility information [20-23]. Given these circumstances, the purpose of this study is to investigate both the positive and negative SSI roles and their effects on the fragility and total risk results related to the containment structure.

Specifically, this paper initially introduces the probabilistic seismic hazard analysis and seismic fragility analysis methodologies within the SPRA framework. The seismic fragility analyses are implemented via the factor of the safety method and the statistical approach of maximum likelihood estimation. In order to quantify the SSI effect from a total risk perspective, the seismic responses of a pressurized water reactor (PWR) containment building structure in three soil conditions, that is, fixed, hard, and soft, are analyzed, and then, these are utilized for the basic information in the SPRA. Two main failure modes, strength and displacement, are taken into account in the risk estimation. Finally, the beneficial and detrimental effects of the SSI on the risk outcomes are quantified, and the results are discussed.

\section{Probabilistic Seismic Hazard Analysis}

A probabilistic seismic hazard analysis (PSHA) is intended to conduct for exploring the potential intensity of an earthquake and what level of ground motions can be expected under uncertainties. Such uncertainties include the aleatory one inherent in the earthquake itself and the epistemic one in the associated earthquake modeling. Technically, the PSHA sets the goal of quantifying uncertainties about the sources, size, distance, and ground motion of future earthquakes, as well as integrating them to produce an explicit description of the distribution of how large ground motions can occur at a site of interest. Typically, the final output of the PSHA is represented by seismic hazard curves, where the annual rates of exceedance $(\lambda)$ are plotted against a seismic hazard intensity parameter.

A conceptual image of the five key steps in the PSHA is shown in Figure 1. A detailed explanation and a description of the PSHA are described in a publication by McGuire [24].

For the purpose of a structural risk assessment, Cornell et al. [25] proposed the following approximated hazard curve equation:

$$
H(\mathrm{PGA})=k_{0} \mathrm{PGA}^{-k}
$$

where the terms $k_{0}$ and $k$ are constant parameters. Equation (1) describes a linear relationship on a log-log plot. Typical values of the log-log slope $k$ are known to be from 1 to 4 , and this is steeper at the western US sites than at the eastern US sites. The specific values of $k$ and $k_{0}$ can be identified according to the hazard information and the appropriate regression analysis. Specifically, the values of $k$ and $k_{0}$ are usually fitted to well represent the seismic hazard information at design basis earthquake (DBE) and maximum considered earthquake (MCE) intensity levels which have $10 \%\left(\lambda=0.0021 \mathrm{yr}^{-1}\right.$ meaning the mean return period $T=475 \mathrm{yr}$ ) and $2 \%$ probabilities of exceedance in 50 years $\left(\lambda=4.04 e-4 \mathrm{yr}^{-1} ; T=2475 \mathrm{yr}\right)$ by using the appropriate regression analysis. Due to this characteristic, this equation tends to overpredict the seismic hazard information out of these ranges since the shape of the hazard curve typically has 


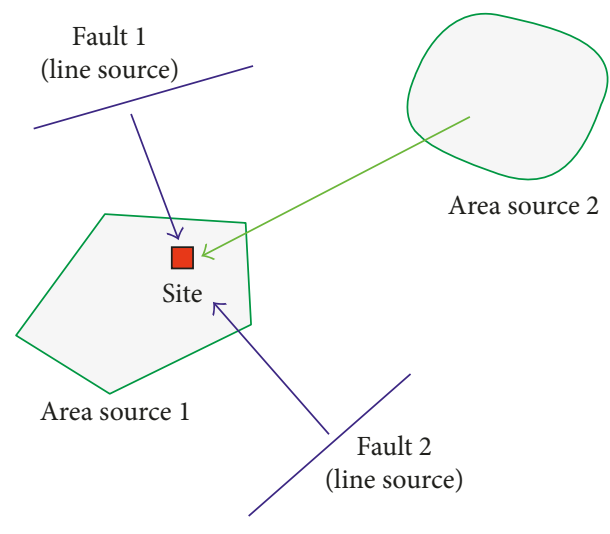

(a)

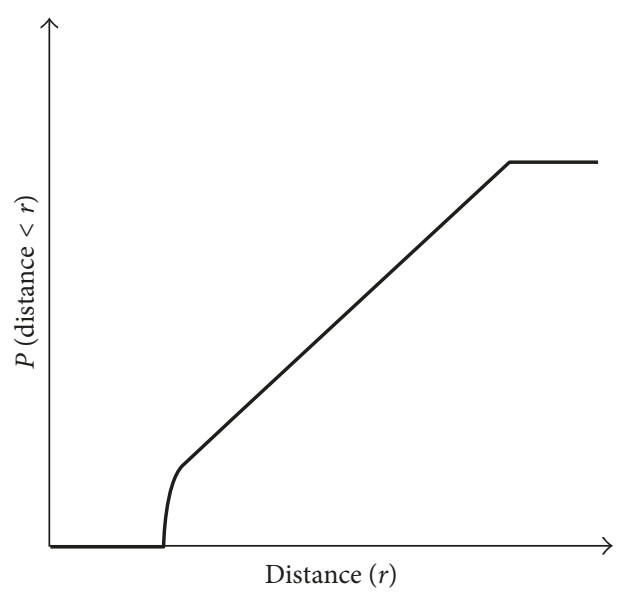

(c)

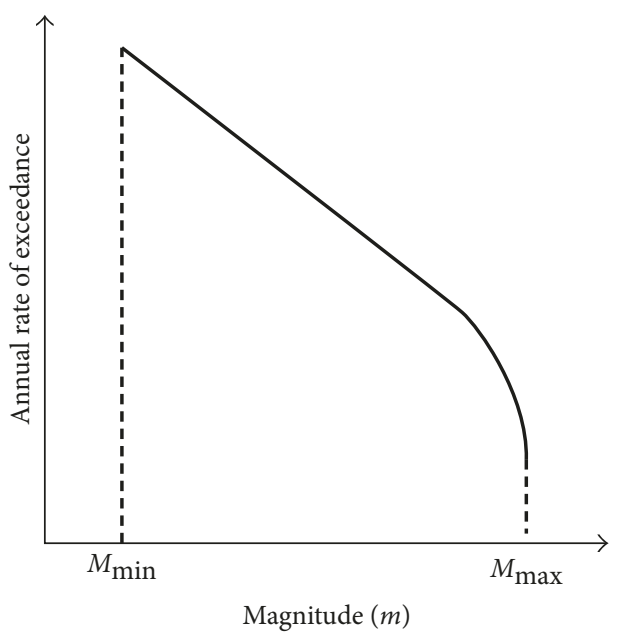

(b)

Probability distribution, given $r$

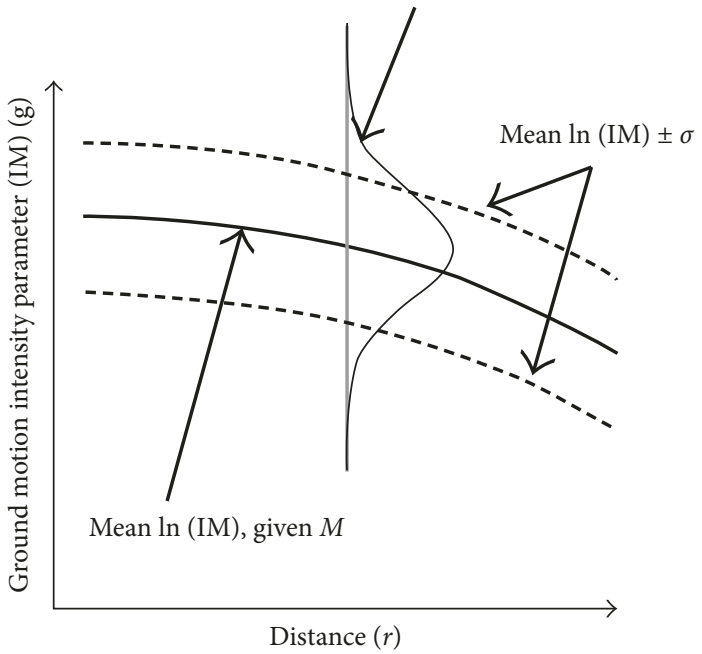

(d)

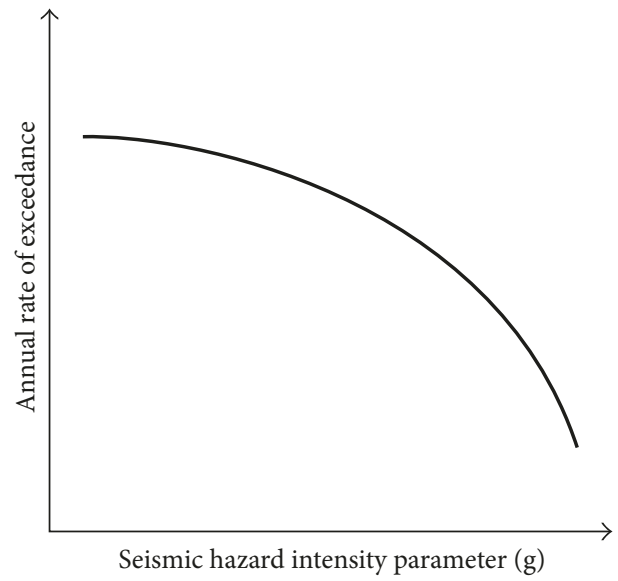

(e)

FIGURE 1: Conceptual image of the five key steps in a PSHA: (a) Step 1: identify the earthquake sources; (b) Step 2: define the distribution of the earthquake magnitude; (c) Step 3: define the distribution of earthquake distances; (d) Step 4: set the ground motion prediction model; (e) Step 5: annual rate of exceeding the seismic hazard intensity as determined by combining steps 1-4. 
a "concave from below" global shape in the log-log scale [26]. But, in other words, because it is conservatively capable of estimating the seismic hazard, it can be quite useful to evaluate risks on the important structural systems such as nuclear power plants and high-rise buildings which highly demand a conservative risk evaluation.

\section{Fragility Analysis}

A seismic fragility analysis is done to determine the relationship between the seismic intensity parameter of an earthquake (PGA in this study) and the corresponding probability of a failure. Specifically, the seismic fragility of a structure, system, and component (SSC) is defined as the conditional failure probability to attain or exceed a specified performance function, $G$, under the given measure of the PGA. It can be stated as follows:

$$
P_{\mathrm{f}}=P(G<0 \mid \mathrm{PGA}) \text {, }
$$

where $G$ is a function of the random variables representing the uncertainties of the material properties, modeling, and loading conditions of an SSC. This can be described in a very simplistic form as follows:

$$
G=C-D,
$$

where $C$ denotes the "capacity" of the SSC corresponding to the specified loading condition and $D$ represents the response "demand" corresponding to the given hazard intensity parameter. The capacity $C$ is usually a representative value determined by the material properties, yield stress, ultimate stress, and other factors based on the design codes and standards. The response demand $D$ is the structural response, as obtained from analyses considering numerical models, earthquake time histories, damping, frequency, coupling, soil-structure interaction, and other related factors, or experimental data, or field observation.

Various methods have been proposed for the fragility analysis of an SSC especially under the seismic intensity of an earthquake hazard based on empirical, experimental, and/or numerical simulation data. These can be broadly grouped according to the following classifications:

(1) Factor of the safety method [9, 27-30]

(2) Statistical inference approaches: maximum likelihood estimation (MLE) [31-33] and Bayesian approach [34-43]

(3) Random vibration approach [44, 45]

(4) Approaches based on Monte Carlo simulation $[11,46,47]$

(5) Reliability-based method [48].

In this study, the factor of the safety method and the MLE-based statistical approach are utilized to evaluate the fragility curve of the NPP containment structure for a case study. The main reasons why we use these methods are as follows: (1) the factor of the safety method is simple and appropriate for the strength-related fragility evaluations; (2) the MLE-based approach makes it possible to create the fragility curve with respect to the displacement-based performance limit; and (3) specifically, the strength failure is more like the stress-based limit problem, so this feature is easily implemented in a factor of the safety method setting. The displacement failure is close to the result of seismic performance; hence, this can be realized through a statistical approach based on the nonlinear seismic analysis results.

3.1. Factor of the Safety Method. The most widely adopted method to evaluate seismic fragilities is that proposed by Kennedy et al. [27]. In this method, the fragility is represented by a set of curves that express the probability of a failure versus ground motion levels at different confidence levels. This means that the seismic fragility illustrates the probabilistic capability of an SSC against ground motion causing structural damage. The probability of a failure of an SSC, $P_{\mathrm{f}}(\mathrm{PGA})$, at any nonexceedance probability level, $Q$, can be obtained from the following equation [28]:

$$
P_{\mathrm{f}}(\mathrm{PGA})=\Phi\left(\frac{\ln \left(\mathrm{PGA} / A_{\mathrm{m}}\right)+\beta_{\mathrm{U}} \Phi^{-1}(\mathrm{Q})}{\beta_{\mathrm{R}}}\right),
$$

where $\Phi(\cdot)$ is the standard Gaussian cumulative distribution function, $A_{\mathrm{m}}$ is the median seismic capacity, $\Phi^{-1}(\cdot)$ is the inverse of the standard Gaussian cumulative distribution function, and $\beta_{\mathrm{R}}$ and $\beta_{\mathrm{U}}$ are the lognormal standard deviations. The two logarithmic standard deviations represent different types of uncertainties. $\beta_{\mathrm{R}}$, referred to as the aleatory uncertainty, is a deviation of the inherent randomness which cannot be reduced by increasing knowledge. $\beta_{\mathrm{U}}$, also known as the epistemic uncertainty, is a deviation of the uncertainty which represents a lack of complete knowledge.

The fragility parameters mentioned above are evaluated using an intermediate random variable termed "the factor of safety" [29]. The medium seismic capacity $A_{\mathrm{m}}$ is defined by (5). Here, $A_{\mathrm{DBE}}$ denotes the PGA values related to the design basis earthquake. The factor of safety $F$ is defined in (6). $F$ is expressed as a product of the capacity factor $F_{\mathrm{C}}$ and the response factor $F_{\mathrm{RS}} . F_{\mathrm{C}}$ can be computed as a product of the strength factor $F_{S}$, which is represented as the ratio of the ultimate strength to the design-code-allowable stress level, and the inelastic energy absorption factor $F_{\mu}$ in (7). In (8), the response factor $F_{\mathrm{RS}}$ can be computed as a product of the spectral shape factor $F_{\mathrm{SA}}$, the damping factor $F_{\delta}$, the modeling factor $F_{\mathrm{M}}$, the mode combination factor $F_{\mathrm{MC}}$, the earthquake component factor $F_{\mathrm{EC}}$, a factor which reflects the reduction of the seismic input with the depth $F_{\mathrm{SD}}$, and a factor to account for the effect of the SSI $F_{S S}$. The logarithmic standard deviation of the factor of safety for the inherent randomness and knowledge uncertainty can be obtained by the square root of the sum of the squares of the individual logarithmic standard deviation of the capacity and response factors in (9) and (10). The subscript $i$ in (9) 
and (10) denotes the individual capacity and response factors in (7) and (8):

$$
\begin{aligned}
A_{\mathrm{m}} & =F \cdot A_{\mathrm{DBE}}, \\
F & =\frac{\text { actual seismic capacity of the compor due to } \mathrm{DBE}}{\text { actual response }} \\
F_{\mathrm{C}} & =F_{\mathrm{S}} \cdot F_{\mu}, \\
F_{\mathrm{RS}} & =F_{\mathrm{SA}} \cdot F_{\delta} \cdot F_{\mathrm{M}} \cdot F_{\mathrm{MC}} \cdot F_{\mathrm{EC}} \cdot F_{\mathrm{SD}} \cdot F_{\mathrm{SS}}, \\
\beta_{\mathrm{R}} & =\left(\sum \beta_{\mathrm{R}_{i}}^{2}\right)^{1 / 2}, \\
\beta_{\mathrm{U}} & =\left(\sum \beta_{\mathrm{U}_{i}}^{2}\right)^{1 / 2} \cdot
\end{aligned}
$$$$
F=\frac{\text { actual seismic capacity of the component }}{\text { actual response due to DBE }}=F_{\mathrm{C}} F_{\mathrm{RS}} \text {, }
$$

The family of the fragility curves is usually expressed by a 95\% confidence level fragility curve, a 50\% confidence level fragility curve meaning the median curve, a 5\% confidence level fragility curve using (4), and a mean fragility curve using the following equation:

$$
P_{\mathrm{f}}(\mathrm{PGA})=\Phi\left[\frac{\ln \left(\mathrm{PGA} / A_{\mathrm{m}}\right)}{\sqrt{\beta_{\mathrm{R}}^{2}+\beta_{\mathrm{U}}^{2}}}\right] .
$$

The method typically depends on data from past studies and expert judgment regarding most factors, except for sitedependent factors. This study focuses on $F_{\mathrm{SS}}$ to investigate the effect of the SSI on the fragility and risk results.

\subsection{Statistical Inference Approach: Maximum Likelihood} Estimation. Without accounting for the epistemic uncertainty in the expression of (4), the fragility curve expression becomes

$$
P_{\mathrm{f}}(\mathrm{PGA})=\Phi\left[\frac{\ln (\mathrm{PGA})-\ln \left(A_{\mathrm{m}}\right)}{\beta_{\mathrm{R}}}\right] .
$$

Given discrete data from numerical simulations, experimental data, and field observations, the parameters of $A_{\mathrm{m}}$ and $\beta_{\mathrm{R}}$ can be identified by utilizing a statistical inference approach. This study adopts the maximum likelihood estimation- (MLE-) based statistical approach in order to determine the two parameters $A_{\mathrm{m}}$ and $\beta_{\mathrm{R}}$ in (12) by fitting the two parameters with the results from numerical simulation data.

The numerical simulation generates some number of failures out of a total number of ground motions at each PGA level. If assuming that the observation of a failure from each ground motion is independent of the observations from other ground motions, the probability of observing $m_{i}$ failures out of $n_{i}$ ground motions with $\mathrm{PGA}=x_{i}$ is given by the binomial distribution:

$$
\begin{aligned}
P\left(m_{i} \text { failures in } n_{i} \text { ground motions }\right)= & \left(\begin{array}{c}
n_{i} \\
m_{i}
\end{array}\right) p_{f, i}{ }^{m_{i}} \\
& \times\left(1-p_{f, i}\right)^{n_{i}-m_{i}},
\end{aligned}
$$

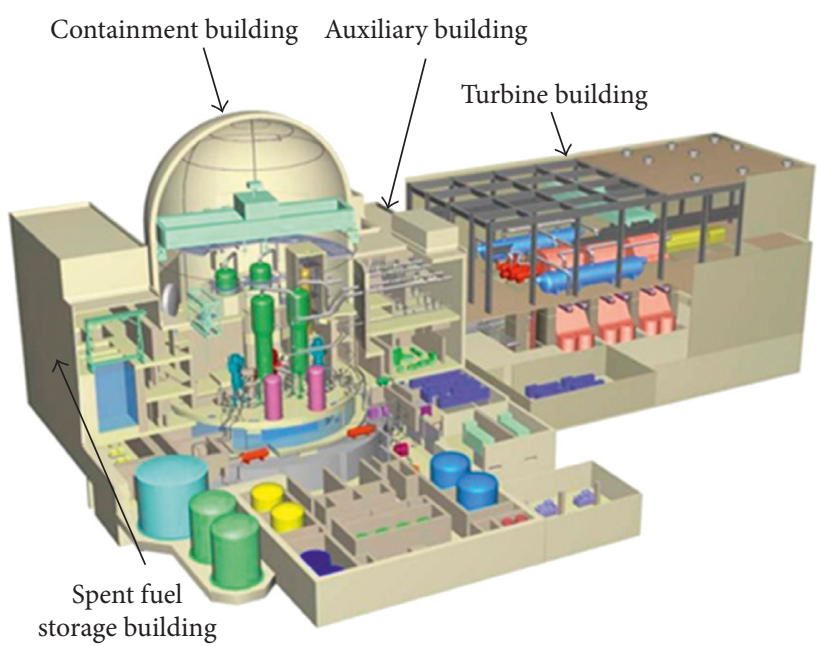

FIGURE 2: PWR nuclear power plant (KHNP).

where $p_{f, i}$ denotes the probability that a ground motion with PGA $=x_{i}$ will cause a failure of the structure according to (12). The MLE approach identifies the parameters of the fragility function of (12) which give the highest probability of having the observed failure data as obtained from the numerical simulation. If we have simulation data at multiple PGA levels, we take the product of the binomial probabilities of (13) at each PGA level to acquire the likelihood function $L$ for all data sets:

$$
L=\prod_{i=1}^{j}\left(\begin{array}{c}
n_{i} \\
m_{i}
\end{array}\right) p_{f, i}^{m_{i}}\left(1-p_{f, i}\right)^{n_{i}-m_{i}}
$$

where $j$ is the number of PGA levels and $\Pi$ denotes a product over all levels. Estimates of the two parameters are made by maximizing this likelihood function. Since it is easier to maximize the natural log of the likelihood function of (14), the numerical representation to find the optimal $A_{\mathrm{m}}$ and $\beta_{\mathrm{R}}$ is formulated as follows:

$$
\underset{A_{\mathrm{m}}, \beta_{\mathrm{R}}}{\arg \max } \ln \left(\prod_{i=1}^{k}\left(\begin{array}{c}
n_{i} \\
m_{i}
\end{array}\right) p_{f, i}^{m_{i}}\left(1-p_{f, i}\right)^{n_{i}-m_{i}}\right) .
$$

The computation for solving (15) can be performed by implementing an appropriate optimization scheme. The MLE approach introduced in this section is applied to the structure in a case study to evaluate the seismic fragility regarding the displacement performance limit based upon the simulation data considering the SSI effect.

\section{Case Study}

A typical PWR NPP primarily consists of a containment building, an auxiliary building, a turbine building, and a spent fuel storage building. Figure 2 shows an advanced power reactor of a Korean NPP as an example. In this study, in order to show the SSI effect on the seismic fragility and risk of the NPP, the containment building structure is considered as an example structure. The NPP containment building is a cylindrical and prestressed reinforced concrete 
structure that houses the nuclear reactor and various types of safety-related equipment.

The methods for the analysis of SSI can be mainly divided into two categories: direct approach and multistep approach (also called the substructure approach) [49]. Any of the two methods can be acknowledged by the regulatory organization (refer to SRP 3.7.2 of the USNRC) when analyzing the SSI problems. In the direct approach, the overall soil-foundationstructure system is modeled and analyzed in a single stage. The input motions are specified along soil boundaries. The use of the direct approach has a strong point to consider the SSI problem in one step and thus to easily deal with the nonlinearities of the soil and structure at the same time. But such an approach demands a large computational power to treat the nonlinear behavior of both the soil and structure simultaneously. In the multistep approach, it uses the principle of superposition to separate two major causes of the SSI: soil amplification effect (site response analysis) and the effect of the dynamic responses of the structure-foundation system on the movement of the supporting soil (seismic response analysis on the structure-foundation system). Due to these characteristics of the multistep approach, it should basically treat the problems as linear or equivalent linear. But it has some merits to relatively reduce the computational cost and also to aid in dividing and analyzing the two SSI effects separately. Given these pros and cons regarding the two approaches, the multistep approach is basically adopted in this study due to the need of multiple SSI analyses to achieve the probabilistic characteristic such as seismic fragility information, but within the structure-foundation response analysis domain, the nonlinearities of the structure are also taken into account. Specifically, the site response analyses are conducted by utilizing an equivalent linear analysis program like SHAKE [50], and the inelastic time-history analyses are performed using the MIDAS GEN [51] program to obtain the nonlinear responses of the structure. The purpose of the site response analysis is to investigate the soil/site amplification phenomenon at the surface due to the flexibility of soil strata. The results of the site response analyses are utilized as input earthquake motions to the soil-structure model in the MIDAS GEN. The detailed descriptions are represented in the following sections.

\subsection{Structure Model and Soil Profile}

4.1.1. Structure Model. The selected containment building structure has a height of approximately $66 \mathrm{~m}$, an outside diameter of about $40 \mathrm{~m}$, a total mass of approximately 29,000 tons, and a fundamental frequency of $3.61 \mathrm{~Hz}$. For efficient dynamic time-history analyses, the lumped-mass stick model of the building derived by calculating the point mass, area, effective shear area, moment of inertia, and other factors for a real shape is used. This model is essentially composed of a containment shell of prestressed concrete and an internal structure of reinforced concrete. For more complete information about the model, a previous study can be referred [52]. In contrast to the previous work, in this study, the stick (beam) element is defined as a nonlinear inelastic element in terms of the Takeda-type trilinear model

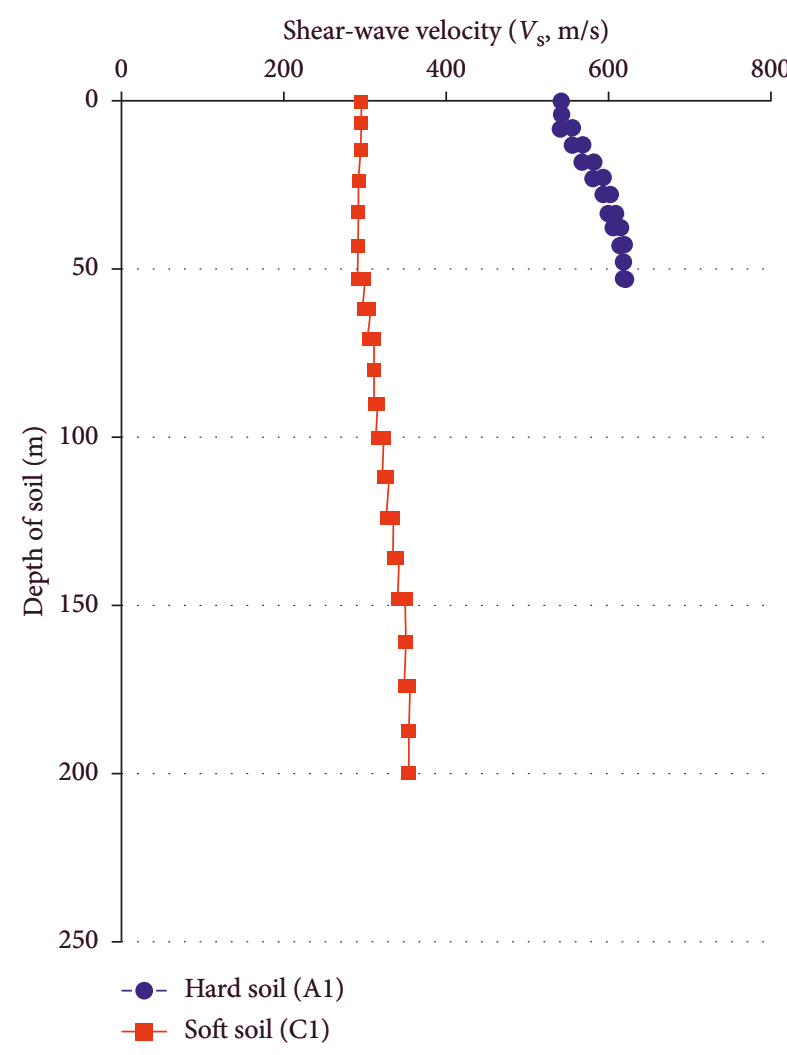

FIgURE 3: Soil profile: $\mathrm{A} 1$ and $\mathrm{C} 1$ conditions.

to describe the shear behavior of the containment building as it experiences the nonlinearity under strong-intensity ground motion. The curve for representing the nonlinear relationship between the shear stress and strain is determined according to the available technical guidelines [53].

4.1.2. Soil Profile. In the standard System 80+ design [54] with respect to the AP1000 and APR1400 models, the soil profiles are categorized mainly into conditions: A (A1), B (B1/B2/B3/B4), and $\mathrm{C}(\mathrm{C} 1 / \mathrm{C} 2 / \mathrm{C} 3)$. In the present study, soil conditions $\mathrm{A} 1$ and $\mathrm{C} 1$ are selected in order to represent hard and soft soil strata, respectively. Figure 3 shows and compares the shear-wave velocity $\left(V_{\mathrm{S}}\right)$ of the two soil conditions of $\mathrm{A} 1$ and $\mathrm{C} 1$ along the depth. The corresponding soil layers and properties of $\mathrm{A} 1$ and $\mathrm{C} 1$ are summarized in Tables 1 and 2 . The additional detailed information on the soil properties is represented in the standard system 80+ design [54].

4.2. Seismic Excitation. It is recommended that the sitespecific earthquake ground motion be utilized for a design earthquake loading according to USNRC RG 1.208 [55]. However, in the site where the observed site-specific earthquake ground motions are rare, the design ground response spectrum (DGRS) defined by USNRC RG 1.60 [56] has been still utilized as a basic spectral shape for the earthquake loading in nuclear power plant design. The fundamental assumption behind this practice is that the DGRS is considered to well represent the rock-site response spectra. Such an assumption is reasonable and conservative because the 
TABLE 1: Soil layers and properties of the condition A1.

\begin{tabular}{lccccc}
\hline Layer & Thickness $(\mathrm{m})$ & $V_{\mathrm{S}}(\mathrm{m} / \mathrm{s})$ & $V_{\mathrm{P}}(\mathrm{m} / \mathrm{s})$ & Damping ratio for S-wave & Damping ratio for P-wave \\
\hline 1 & 1.22 & 541 & 1325 & 0.005 & 0.002 \\
2 & 1.22 & 555 & 1359 & 0.009 & 0.003 \\
3 & 1.52 & 568 & 1390 & 0.012 & 0.004 \\
4 & 1.52 & 582 & 1426 & 0.013 & 0.004 \\
5 & 1.52 & 594 & 1455 & 0.018 & 0.005 \\
6 & 1.52 & 602 & 1475 & 0.019 & 0.006 \\
7 & 1.52 & 608 & 1490 & 0.021 & 0.006 \\
8 & 1.52 & 614 & 1504 & 0.022 & 0.007 \\
9 & 1.52 & 617 & 1511 & 0.024 & 0.007 \\
10 & 1.52 & 618 & 1515 & 0.025 & 0.008 \\
11 & 1.52 & 618 & 1515 & & 0.008 \\
Base rock & & 1524 & 2489 & & \\
\hline
\end{tabular}

TABLE 2: Soil layers and properties of the condition C1.

\begin{tabular}{lccccc}
\hline Layer number & Thickness $(\mathrm{m})$ & $V_{\mathrm{S}}(\mathrm{m} / \mathrm{s})$ & $V_{\mathrm{P}}(\mathrm{m} / \mathrm{s})$ & Damping ratio for S-wave & Damping ratio for P-wave \\
\hline 1 & 2.13 & 296 & 724 & 0.013 & 0.004 \\
2 & 2.44 & 293 & 718 & 0.025 & 0.008 \\
3 & 2.74 & 292 & 716 & 0.034 & 0.042 \\
4 & 2.74 & 291 & 714 & 0.047 & 0.014 \\
5 & 3.05 & 292 & 716 & 0.050 & 0.016 \\
6 & 3.05 & 300 & 734 & 0.052 & 0.017 \\
7 & 2.74 & 305 & 746 & 0.057 & 0.017 \\
8 & 2.74 & 308 & 755 & 0.060 & 0.019 \\
9 & 2.74 & 312 & 764 & 0.063 & 0.021 \\
10 & 3.05 & 315 & 772 & 0.064 & 0.021 \\
11 & 3.05 & 322 & 789 & 0.065 & 0.022 \\
12 & 3.66 & 327 & 802 & 0.065 & 0.022 \\
13 & 3.66 & 334 & 818 & 0.065 & 0.022 \\
14 & 3.66 & 341 & 835 & 0.064 & 0.021 \\
15 & 3.66 & 349 & 856 & 0.066 & 0.022 \\
16 & 3.96 & 349 & 856 & 0.066 & 0.022 \\
17 & 3.96 & 354 & 868 & 0.067 & 0.022 \\
18 & 3.96 & 355 & 869 & 0.068 & 0.023 \\
19 & 3.96 & 354 & 867 & & \\
Base rock & & 1524 & 2489 & & \\
\hline
\end{tabular}

DGRS is utilized for the seismic design and risk assessment in nuclear plants. Hence, because this research does not focus on a specific site for design purposes but on the SSI effect according to uncertainties in the soil properties, probable earthquake ground motions are selected by taking various earthquake magnitudes, distances, intensity levels, and other measures into account. In addition, such earthquake ground motions are selected such that the overall response spectral shape of the selected ground motions follows the DGRS shape. Table 3 shows twenty sets of selected earthquake ground motions from the Pacific Earthquake Engineering Research (PEER) Center (URL: http://peer.berkeley.edu/nga/). Figure 4 plots the response spectra obtained from the seismic response analysis results of a 5\% damped linear-elastic single-degree-offreedom (SDOF) model subjected to each earthquake ground motion normalized to the PGA of $1 \mathrm{~g}$, in this case the mean response spectrum and the mean-plus-one-standard-deviation response spectrum.

4.3. Site Response Analysis. The soil deposit alters the ground surface motion compared to the original earthquake motions occurring in bedrock. This is attributed to the fact that the seismic waves travel through the soil stratum, and accordingly, the soil plays a significant role in determining the characteristics of the ground surface motion. The influence of the local soil conditions on the earthquake motion can be quantified via a site response analysis. In this regard, site response analyses are performed for the $\mathrm{A} 1$ and $\mathrm{C} 1$ soil conditions, and these determine the input foundation motions to the NPP containment building structure. This study assumes the earthquake ground motions introduced in Section 4.2 as the motions occurring in the bedrock. The analyses are run on the assumption that the soil deposit is horizontally layered over a half space of rock, and the principle of one-dimensional propagation of seismic waves in a vertical direction is applied. Figure 5 shows the mean response spectra of the $5 \%$ damped linear-elastic SDOF model subjected to foundation input motions as determined from the site response analyses using 20 sets of earthquake ground motions (normalized to a PGA of $1 \mathrm{~g}$ ) as introduced in Section 4.2. This compares the mean response spectra of the bedrock, hard soil, and soft soil conditions. It is found 
TABLE 3: Selected earthquake ground motions.

\begin{tabular}{|c|c|c|c|c|c|c|}
\hline Number & Name & Year & Station name & ${ }^{*} \mathrm{M}$ & ${ }^{*}$ Dis. & PGA (g) \\
\hline 1 & Imperial Valley-06 & 1979 & El Centro Array \#5 & 6.53 & 3.95 & 0.375 \\
\hline 2 & Imperial Valley-06 & 1979 & El Centro Array \#6 & 6.53 & 1.35 & 0.442 \\
\hline 3 & Loma Prieta & 1989 & Gilroy-Gavilan College & 6.93 & 9.96 & 0.294 \\
\hline 4 & Northridge-01 & 1994 & Jensen Filter Plant & 6.69 & 5.43 & 0.518 \\
\hline 5 & Northridge-01 & 1994 & Sylmar Converter Station & 6.69 & 5.35 & 0.594 \\
\hline 6 & Kobe, Japan & 1995 & KJMA & 6.90 & 0.96 & 0.854 \\
\hline 7 & Kobe, Japan & 1995 & Takarazuka & 6.90 & 0.27 & 0.645 \\
\hline 8 & Kocaeli, Turkey & 1999 & Gebze & 7.51 & 10.92 & 0.241 \\
\hline 9 & Chi-Chi, Taiwan & 1999 & TCU052 & 7.62 & 0.66 & 0.375 \\
\hline 10 & Chi-Chi, Taiwan & 1999 & TCU068 & 7.62 & 0.32 & 0.564 \\
\hline 11 & Borrego Mtn & 1968 & San Onofre (South Carolina Edison) & 6.63 & 129.1 & 0.045 \\
\hline 12 & Hector Mine & 1999 & Heart Bar State Park & 7.13 & 61.21 & 0.070 \\
\hline 13 & Kern County & 1952 & LA-Hollywood Stor FF & 7.36 & 114.6 & 0.058 \\
\hline 14 & Kocaeli, Turkey & 1999 & Botas & 7.51 & 126 & 0.089 \\
\hline 15 & Lytle Creek & 1970 & Castaic (Old Ridge Route) & 5.33 & 103.4 & 0.026 \\
\hline 16 & Anza-02 & 2001 & San Jacinto CDF Fire Station 25 & 4.92 & 51.3 & 0.054 \\
\hline 17 & San Fernando & 1971 & Hemet Fire Station & 6.61 & 139.1 & 0.047 \\
\hline 18 & Landers & 1992 & Yermo Fire Station & 7.28 & 23.62 & 0.222 \\
\hline 19 & Denali, Alaska & 2002 & Carlo (temp) & 7.9 & 50.94 & 0.087 \\
\hline 20 & Duzce, Turkey & 1999 & Mudurnu & 7.14 & 34.3 & 0.114 \\
\hline
\end{tabular}

${ }^{*}$ Dis.: closest distance to a fault rupture $(\mathrm{km}) ;{ }^{*} \mathrm{M}$ : magnitude.

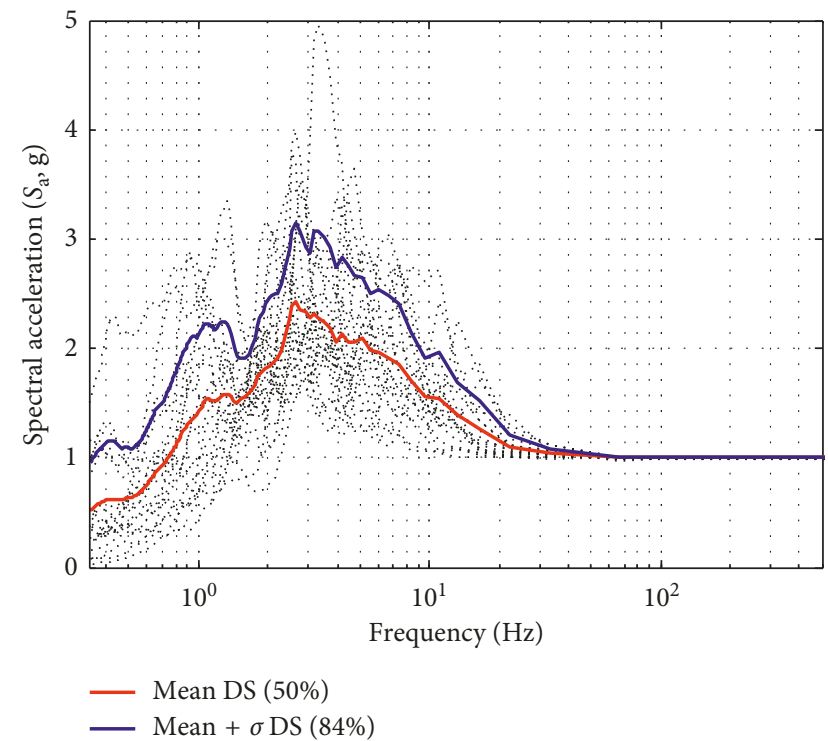

FIGURE 4: Response spectra under earthquake ground motions normalized to a PGA of $1.0 \mathrm{~g}$.

that the motions in soft soil are more amplified than those in the hard soil and bedrock conditions. Specifically, the soft soil amplified the spectral accelerations over all frequencies, and the amplification was prominent in $1-2 \mathrm{~Hz}$ and $3-5 \mathrm{~Hz}$. Such an observation comes from the fact that the fundamental frequency of the soft soil-structure system is shifted due to the increased flexibility of the soil. However, the hard soil did not make the site responses amplified relatively. Especially, the hard soil did not change the spectral acceleration in below $1.5 \mathrm{~Hz}$ at all. The reason for this is that the hard soil having the shear-wave velocity of about $600 \mathrm{~m} / \mathrm{s}$ does not change the main dynamic characteristic of the

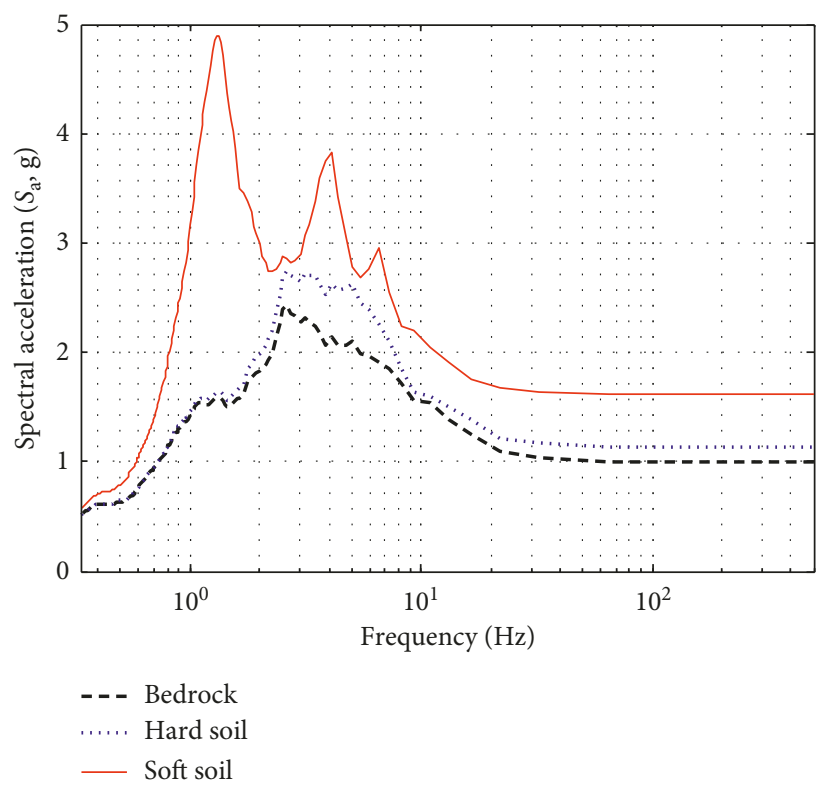

Figure 5: Mean response spectra obtained from site response analyses in bedrock, hard soil, and soft soil conditions.

structure, but relatively softer characteristics than the bed rock bring the amplification to the overall responses in the range greater than $1.5 \mathrm{~Hz}$.

4.4. Seismic Response Analysis. A sufficiently accurate consideration of soil behavior can be obtained if the soil stiffness and damping coefficients of a circular massless foundation on the soil stratum are evaluated by the frequency independent expression. The stiffness and damping coefficients of the soil stratum are defined by 
TABLE 4: Average soil dynamic properties of the different soil cases A1 and C1.

\begin{tabular}{|c|c|c|}
\hline \multirow[b]{2}{*}{ Properties of soil } & \multicolumn{2}{|c|}{ Soil cases } \\
\hline & $\begin{array}{c}\text { Hard } \\
\text { A1 }\end{array}$ & $\begin{array}{c}\text { Soft } \\
\mathrm{C} 1\end{array}$ \\
\hline Bulk modulus, $G(\mathrm{~Pa})$ & $3.2704 e+009$ & $2.1150 e+008$ \\
\hline Horizontal stiffness of the soil stratum, $K_{\mathrm{h}}(\mathrm{N} / \mathrm{m})$ & $3.1349 e+011$ & $2.0273 e+010$ \\
\hline Rocking stiffness of the soil stratum, $K_{\mathrm{r}}(\mathrm{N} / \mathrm{m})$ & $1.0418 e+014$ & $6.7375 e+012$ \\
\hline Vertical stiffness of the soil stratum, $K_{\mathrm{v}}(\mathrm{N} / \mathrm{m})$ & $3.9186 e+011$ & $2.5342 e+010$ \\
\hline Horizontal damping coefficient, $C_{\mathrm{h}}(\mathrm{Ns} / \mathrm{m})$ & $2.8167 e+009$ & $7.1629 e+008$ \\
\hline Rocking damping coefficient, $C_{\mathrm{r}}(\mathrm{Ns} / \mathrm{m})$ & $2.4419 e+011$ & $6.2099 e+010$ \\
\hline Vertical damping coefficient, $C_{\mathrm{v}}(\mathrm{Ns} / \mathrm{m})$ & $5.2047 e+009$ & $1.3236 e+009$ \\
\hline
\end{tabular}

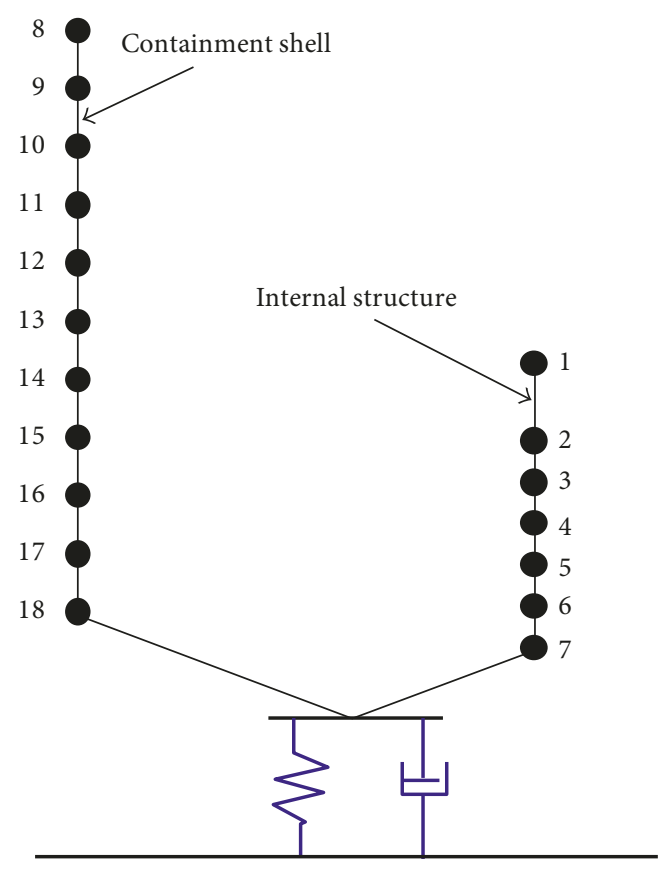

(a)

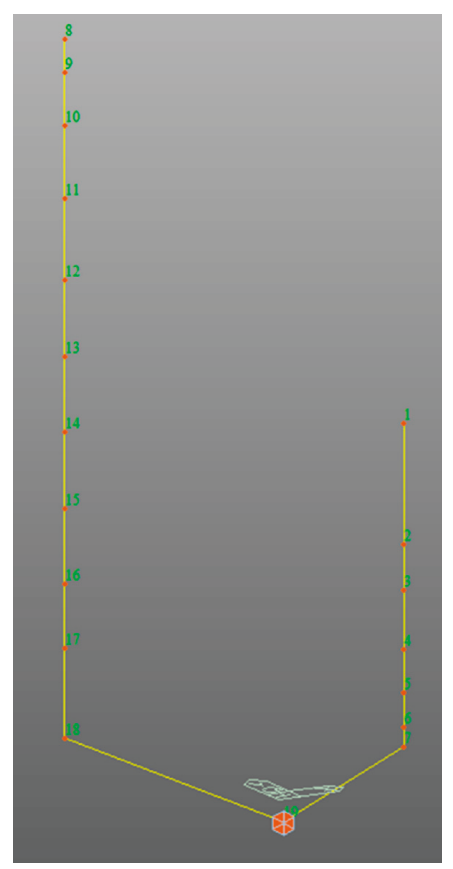

(b)

FIGURE 6: Lumped-mass stick model for the NPP containment building: (a) conceptual model; (b) numerical model in MIDAS GEN.

$$
\begin{aligned}
& K_{\mathrm{h}}=\frac{8 G R}{2-v}, \\
& K_{\mathrm{r}}=\frac{8 G R^{3}}{3(1-v)}, \\
& K_{\mathrm{v}}=\frac{4 G R}{1-v}, \\
& C_{\mathrm{h}}=\frac{4.6 G R^{2}}{(2-v) V_{\mathrm{s}}}, \\
& C_{\mathrm{r}}=\frac{0.4 G R^{4}}{(1-v) V_{\mathrm{s}}}, \\
& C_{\mathrm{v}}=\frac{3.4 R^{2}}{1-v} \sqrt{G \rho},
\end{aligned}
$$

where $K_{\mathrm{h}}, K_{\mathrm{r}}$, and $K_{\mathrm{v}}$ represent the horizontal, rocking, and vertical stiffness of the soil stratum, respectively; $C_{\mathrm{h}}, C_{\mathrm{r}}$, and $C_{\mathrm{v}}$ represent the horizontal, rocking, and vertical viscous damping coefficients for the radiation soil damping, respectively; $G$ is the soil shear modulus; $V_{s}$ is the shear-wave velocity of the soil; $R$ is the radius of circular footing; $\nu$ is Poisson's ratio of the soil; and $\rho$ is the density of the soil. The average shear-wave velocity representing the various soil layers can be computed as follows:

$$
V_{\mathrm{s}}=\frac{\sum_{i=1}^{n} d_{i}}{\sum_{i=1}^{n}\left(d_{i} / V_{s i}\right)},
$$

where $d_{i}$ is the thickness of the soil layer, $V_{s i}$ is the shearwave velocity of the corresponding soil layer, and $n$ is the number of the soil layers. Table 4 represents the average soil dynamic properties of the two different soil cases A1 and C1. 


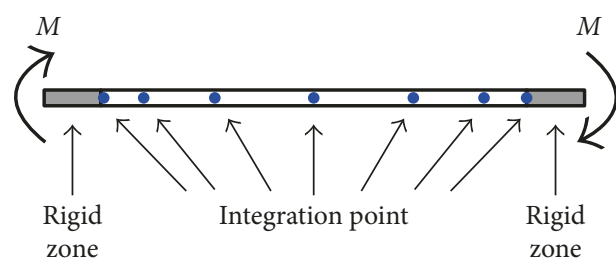

(a)

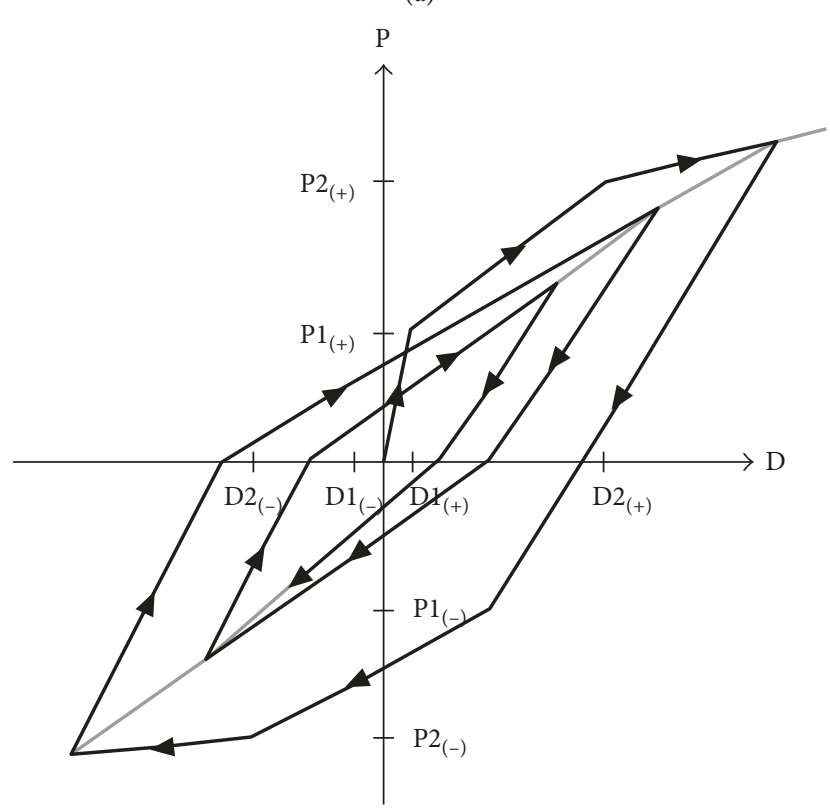

(b)

Figure 7: Takeda-type trilinear inelastic model for beam-column elements [51]: (a) distributed-type hinge model; (b) Takeda-type trilinear behavior.

These properties are utilized as spring and damper links at the bottom of the containment structure model.

Figure 6 shows the numerical model for the containment structure, constructed within a MIDAS GEN framework. The fundamental frequencies of such models with different soil conditions obtained from mode analyses are $3.33 \mathrm{~Hz}$ for $\mathrm{A} 1$ and $1.85 \mathrm{~Hz}$ for $\mathrm{C} 1$, respectively. The stick (beam) element is defined by a nonlinear inelastic element (in this study, Takeda-type trilinear model) for the shear behavior of the containment building since it experiences the nonlinearity in the strong intensity of motion. The turning points for the shear stress and strain relationship are decided according to the technical guidelines [53]. The distributedtype hinge model is used for the inelastic hinge properties of beam-column elements (Figure $7(\mathrm{a})$ ). Specifically, we assume inelastic behavior throughout the member. The plastic hinge locations in the length direction of a member are defined as the integration points. The number of integration points can be between 3 and 20 in the MIDAS GEN. The flexibility matrix of a section, which represents the distribution of internal forces, is calculated through the integration points. The hinge behaviors can be expressed by force-deformation relationships in each axis direction, and the hinge hysteresis behavior of the flexural components can be expressed by the relationships of moment and angle of rotation. Figure $7(\mathrm{~b})$ shows the hysteresis rule of the Takedatype trilinear model with regard to the force $(P)$ and displacement $(D)$ utilized in this study. $P 1$ and $P 2$ are the first and second yield strength, respectively. $D 1$ and $D 2$ are the first and second yield deformation, respectively.

The nonlinear seismic response analyses are conducted under the foundation input motions acquired from Section 4.3. These analyses consider three soil conditions: (1) rock (no SSI), (2) hard soil, and (3) soft soil. The rock condition is accomplished using the fixed boundary condition at the bottom of the structure. The hard soil and soft soil conditions are realized by formulating the soil impedance functions. Figure 8 shows the maximum displacements at the top of the NPP containment building structure with the three different soil conditions according to the 20 earthquake ground motions normalized to PGA values of $0.1 \mathrm{~g}$ to $2.0 \mathrm{~g}$. The median, 25th percentiles, 75th percentiles, and the whiskers which extend to the most extreme points except for the outliers are presented based on the assumption that the obtained maximum displacements are normally distributed. It is observed that the responses and the effect of the nonlinearity of the containment building are much larger in the soft soil condition than in the other soil conditions. Specifically, the displacement at no SSI and hard soil conditions approximately has a similar pattern at 25th percentiles, median, and 75 th percentiles, but the result on the soft soil is almost 5 to 10 times higher in all PGA ranges than the hard soil. The reason for this observation is that the soft soil condition plays a sort of role of a seismic isolator at the base of the NPP structure and accordingly induces the large displacement at the top of the structure. Also, the seismic energy dissipation occurs intensively in the soft soil layer, so the nonlinearity of the responses seems prominent in the soft soil condition compared to the other conditions.

Figure 9 illustrates the mean floor response spectra (FRS) at the top of the internal structure of the containment building in the three different soil conditions. This result shows that the secondary systems attached to the floor of the internal structure of the containment building such as the equipment and piping having low frequencies $(0.5-2 \mathrm{~Hz})$ are more vulnerable in the soft soil condition than in the hard soil or rock conditions. On the contrary, the secondary systems with the relatively high frequencies (i.e., more than $30 \mathrm{~Hz}$ ) are more fragile in other soil conditions than in the soft soil condition. It is noteworthy that the maximum spectral response in the soft soil condition is less amplified than that in the other soil conditions. Consideration of the SSI effect shifts the dominant frequency range to the lower side because the soil acts as a flexible spring at the bottom of the structure and causes the fundamental period of the structure to become elongated. This also reduces the internal structural responses due to the effect of the energy dissipation mechanism of the soil. Owing to these characteristics, the SSI has a beneficial or detrimental effect on the seismic responses of structures. In the following sections, the quantitative SSI effect is investigated from the fragility and risk perspectives regarding the two major failure modes. 

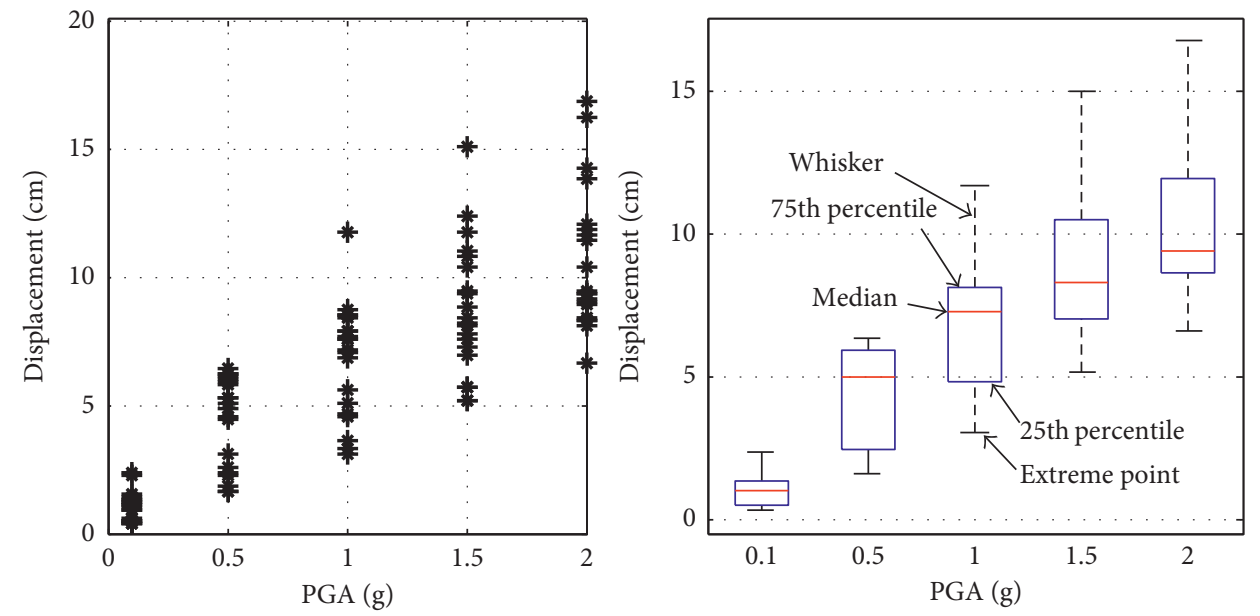

(a)
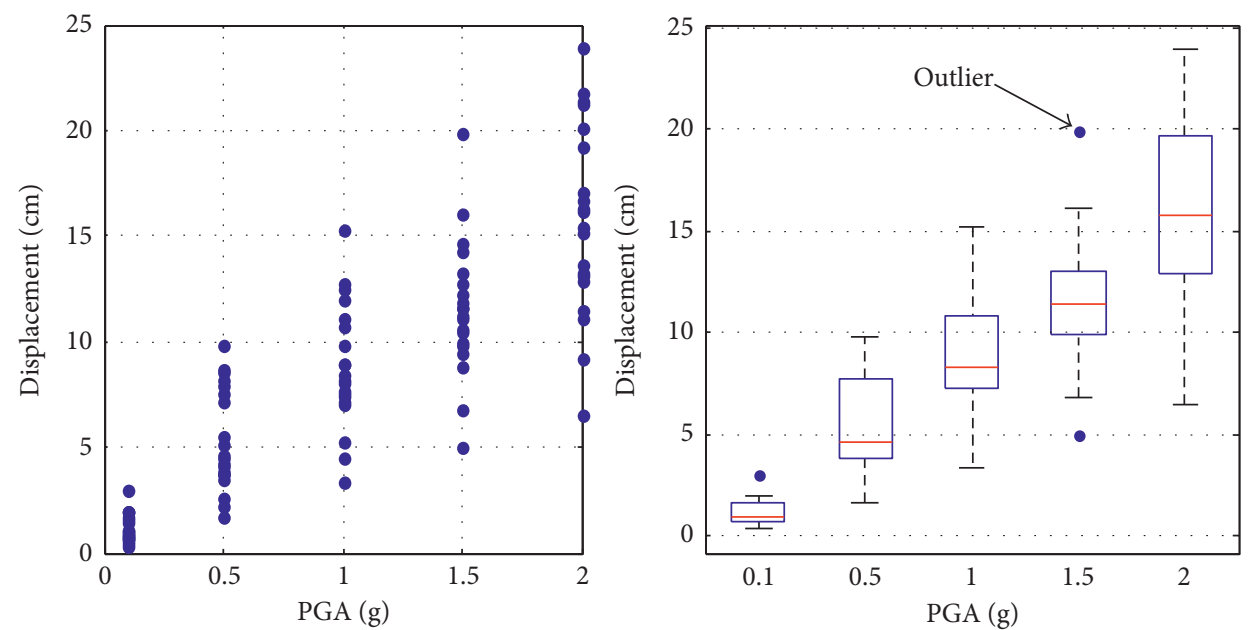

(b)
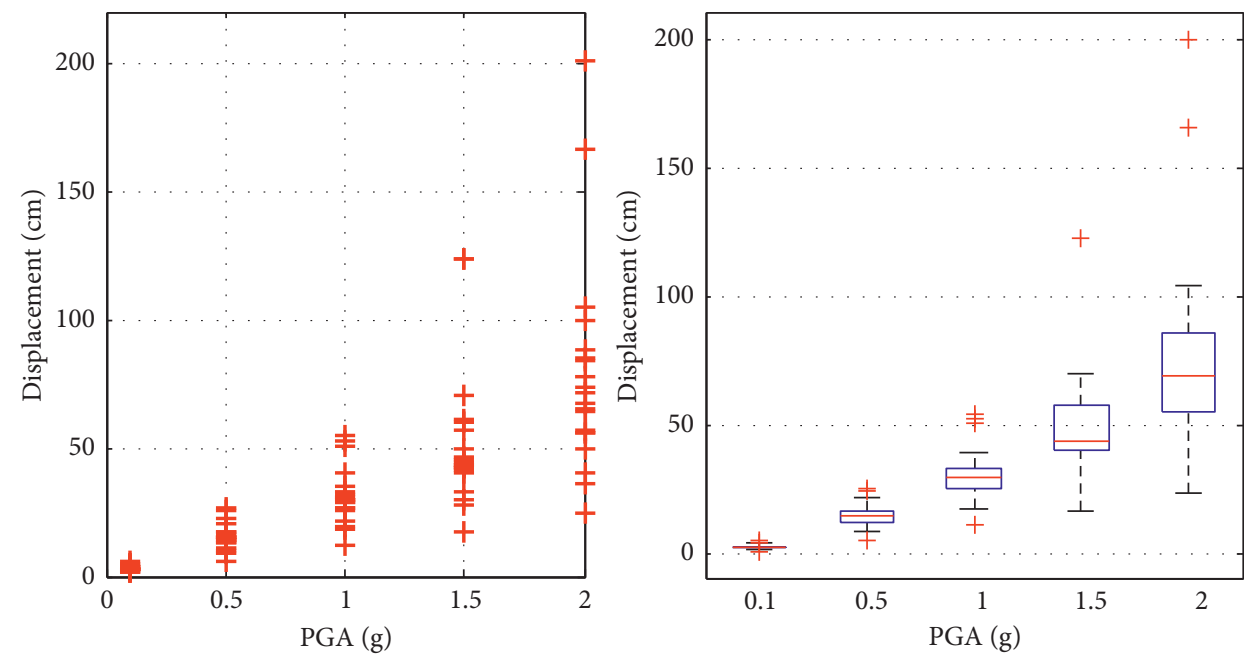

(c)

FIgURE 8: Maximum top displacement of the NPP containment building for three soil conditions under 20 earthquake ground motions normalized to PGA of $0.1 \mathrm{~g}-2 \mathrm{~g}$ : (a) no SSI; (b) hard soil; (c) soft soil. 


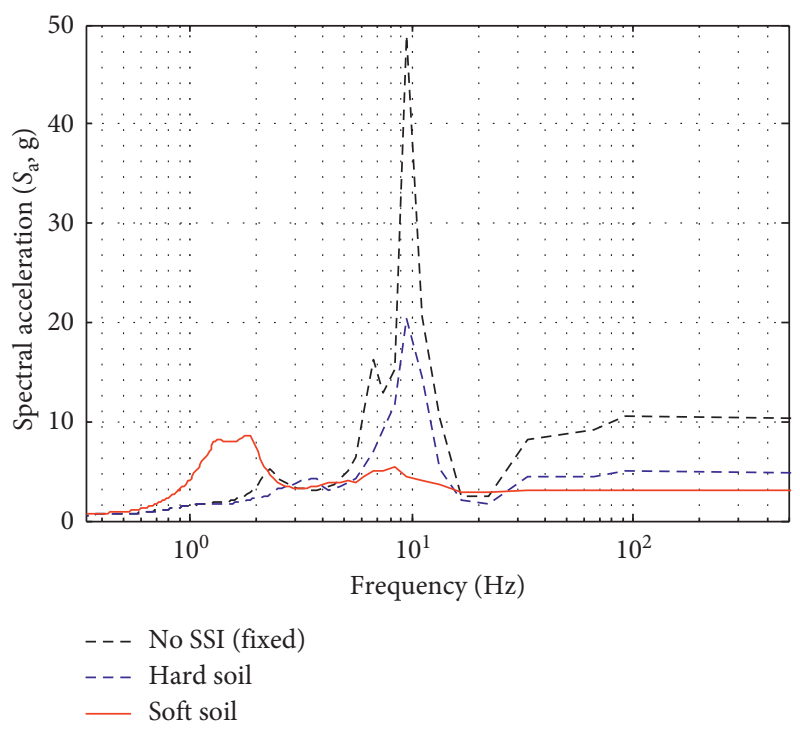

Figure 9: Mean floor response spectra at the top of the internal structure.

\subsection{Seismic Fragility Analysis regarding Two Major Failure Modes: Strength and Displacement}

4.5.1. Case 1: Strength Failure Mode. To investigate the seismic fragility regarding the failure mode of the design strength, the factor of the safety method introduced in Section 3.1 is applied. In the factor of the safety method, the three key parameters $A_{\mathrm{m}}, \beta_{\mathrm{R}}$, and $\beta_{\mathrm{U}}$ in (5), (9), and (10) need to be evaluated in order to develop the fragility curve. The value of $A_{\mathrm{m}}$ is calculated according to the product of the overall safety factor $F$ and design basis earthquake $A_{\mathrm{DBE}}$. The value of $F$ is the end result obtained after the multiplication of various factors in (7) and (8). In this study, except for the SSI factor $F_{\mathrm{SS}}$, other factors, including $\beta_{\mathrm{R}}$ and $\beta_{\mathrm{U}}$, are derived from the generic data presented by numerous studies performed involving nearly 100 nuclear power plants [5, 57]. The value of $F_{\mathrm{SS}}$ is estimated by dividing the mean FRS of the fixed base by that of the SSI analysis [23]. The obtained values of $F_{\mathrm{C}}$ and $F_{\mathrm{SA}} \cdot F_{\delta} \cdot F_{\mathrm{M}} \cdot F_{\mathrm{MC}} \cdot F_{\mathrm{EC}} \cdot F_{\mathrm{SD}}$ are 2.2 and 1.8 , respectively. $\beta_{\mathrm{R}}$ and $\beta_{\mathrm{U}}$ are determined to be 0.26 and 0.30 from generic data. The calculated value of $F_{\mathrm{SS}}$ is 6.13 for the soft soil condition and 2.45 for the hard soil condition. $A_{\mathrm{DBE}}$ is set to $0.3 \mathrm{~g}$ for this structure. Figure 10 shows the family of seismic fragility curves including the median, the $95 \%$ confidence level (CL), the 5\% CL, and the mean in the soft soil and hard soil conditions. Figure 11 compares the median seismic hazard curves in the fixed, hard soil, and soft soil conditions. From these figures, consideration of the SSI has a beneficial influence on the results of the seismic fragility evaluation. This occurs due to the fact that the soft soil deposit increases the system damping effect, leading to a reduction of the induced internal forces. To be more specific, as mentioned previously, the soft soil condition acts like a seismic isolator at the base of the NPP containment structure. Therefore, such a phenomenon brought the excessive displacement at the top of the structure (Figure 8). But this causes the structure to perform rigid body motion

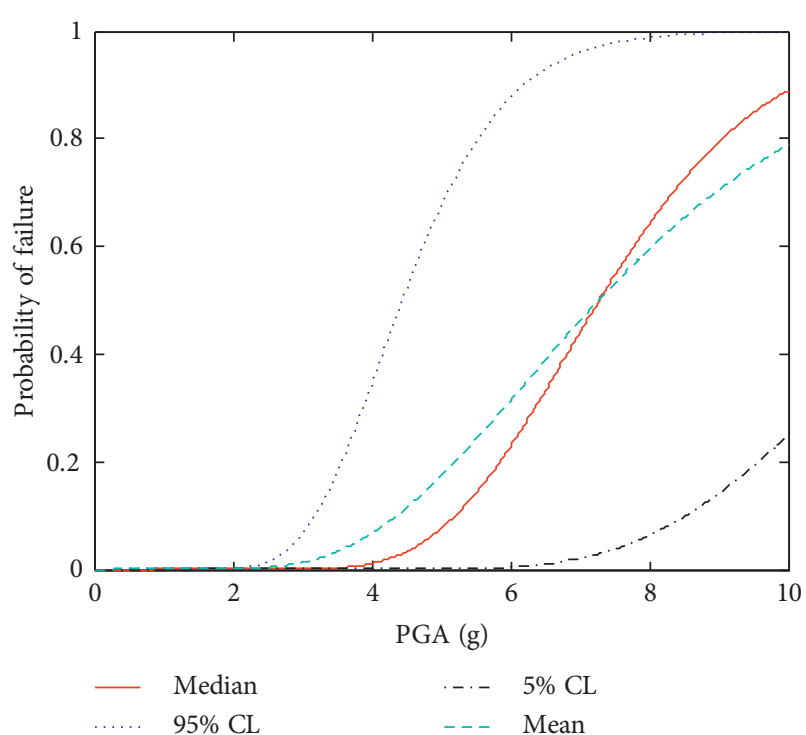

(a)

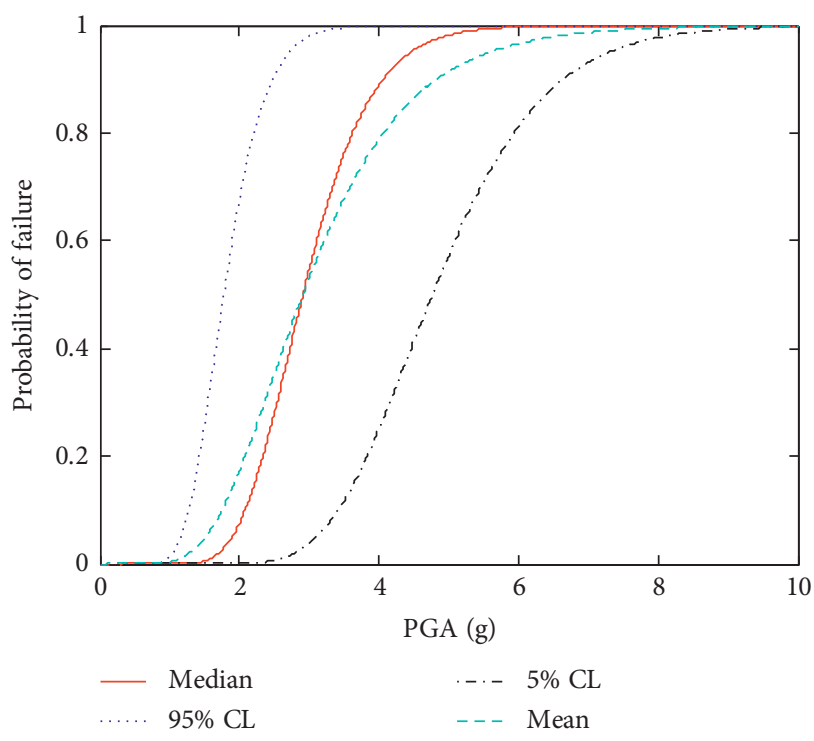

(b)

FIGURE 10: Seismic fragility curves: $5 \%$ confidence level, median, 95\% confidence level, and mean (case 1). (a) Soft soil. (b) Hard soil.

and, accordingly, reduces acceleration responses (Figure 11) and internal deformation in the structure. These results are finally reflected in the strength failure mode for the structure, and these become main reasons to have its seismic fragility results, represented in Figure 11.

4.5.2. Case 2: Displacement Failure Mode. In the performance-based structural design, the displacement is an indicator which can represent whether a failure occurs or not in the structure. Because the containment building is in very close proximity to other utility buildings, a collision between the containment structure and other buildings, meaning its pounding to others, is a critical failure mode under an earthquake event. Thus, this study defines a failure in the containment building structure when excessive displacement 


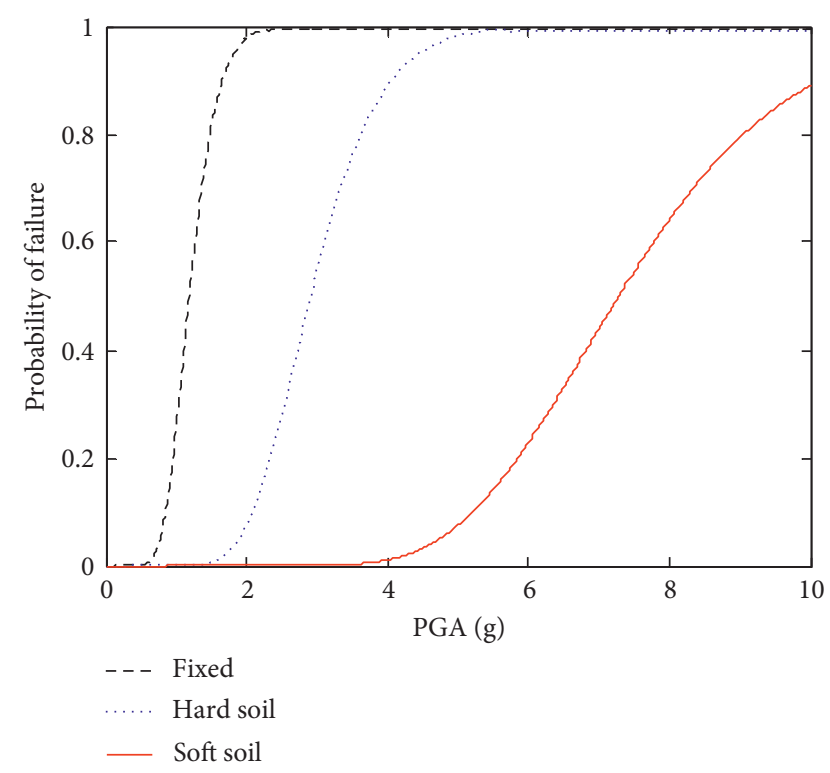

Figure 11: Comparison of median seismic hazard curves: fixed, hard soil, and soft soil conditions (case 1).

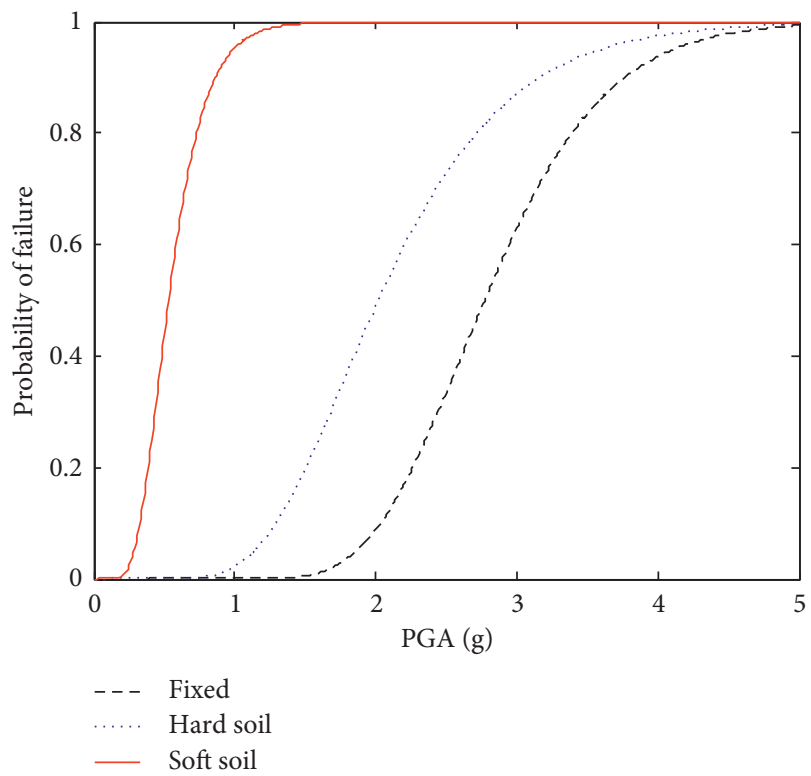

FIGURE 12: Median seismic fragility curves: fixed, hard soil, and soft soil (case 2).

takes place above the allowable seismic gap, that is, about $15 \mathrm{~cm}$. Figure 12 shows the median seismic fragility curves for this failure mode by using the seismic response results of Section 4.4 and the MLE-based statistical approach in Section 3.2. Figure 13 illustrates the median and $90 \%$ confidence interval (CI) of the seismic fragility curves. From these results, we can see that considering the SSI effect in the failure mode in case 2 has a detrimental impact on the seismic fragility, unlike the strength failure mode of case 1 . This occurs because the soft soil deposit brings flexibility to the bottom of the structure and induces large structural displacement at the top compared to the rock and hard soil conditions.

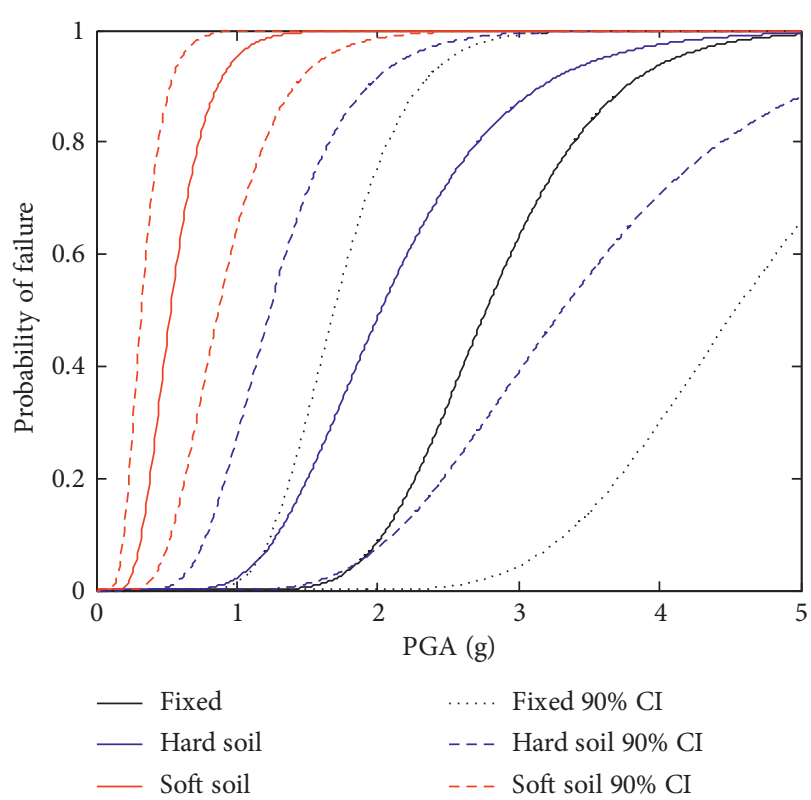

FIgURE 13: Seismic fragility curves of median and 90\% CI: fixed, hard soil, and soft soil (case 2).

4.6. Risk Analysis. In this section, we investigate how the SSI effect changes the total risk in the specific seismic hazard information. Within the US, the US Geological Survey (USGS: http://earthquake.usgs.gov/hazards /products/) provides seismic hazard information at any place of interest. For example, Figure 14 shows the DBE- and MCE-level seismic hazard maps of the US. Therefore, based on the obtained hazard information of the USGS and on (1), the seismic hazard curve at any site of interest in the US can be developed by identifying the $k_{0}$ and $k$ values for seismic risk calculation purposes.

In this study, we consider the three representative sites Los Angeles in California $\left(34.045^{\circ},-118.247^{\circ}\right)$, Memphis in Tennessee $\left(35.145^{\circ},-90.044^{\circ}\right)$, and Charleston in South Carolina $\left(32.790^{\circ},-79.936^{\circ}\right)$ to account for the different seismic characteristics throughout the US (for the graphical information on the locations, Figure 14). Specifically, the PGA-based seismic hazard information for these sites was extracted from the USGS seismic hazard database and is represented as blue circles in Figure 15. In addition, for the conservative seismic risk estimation, the log-log linear form of (1) was used to approximate the given discrete seismic hazard information. The values of the parameters $k$ and $k_{0}$ were identified from the least squares method such that the equation could well describe the hazard information in the DBE and MCE levels (i.e., the red dashed lines in Figure 15). The approximated log-log linear hazard curves finally obtained from such an approach are also represented along with the discrete hazard data. As shown in Figure 15, it is observed that the log-log linear seismic hazard curve could well predict the DBE- and MCE-level hazard information but overestimate outside of these ranges. Such a characteristic of the log-log linear hazard curve can enable the conservative evaluation of $\mathrm{CDF}$. 


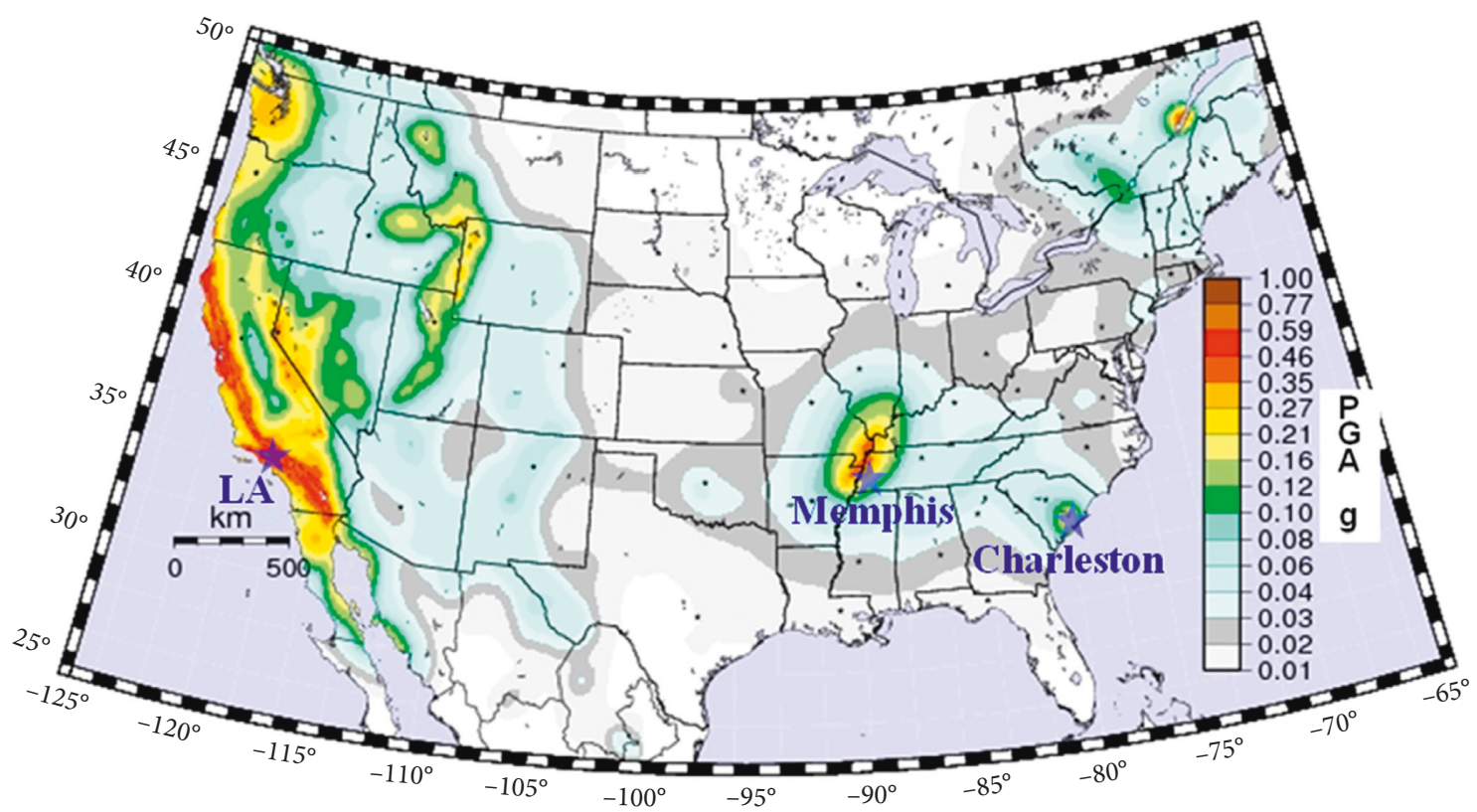

(a)

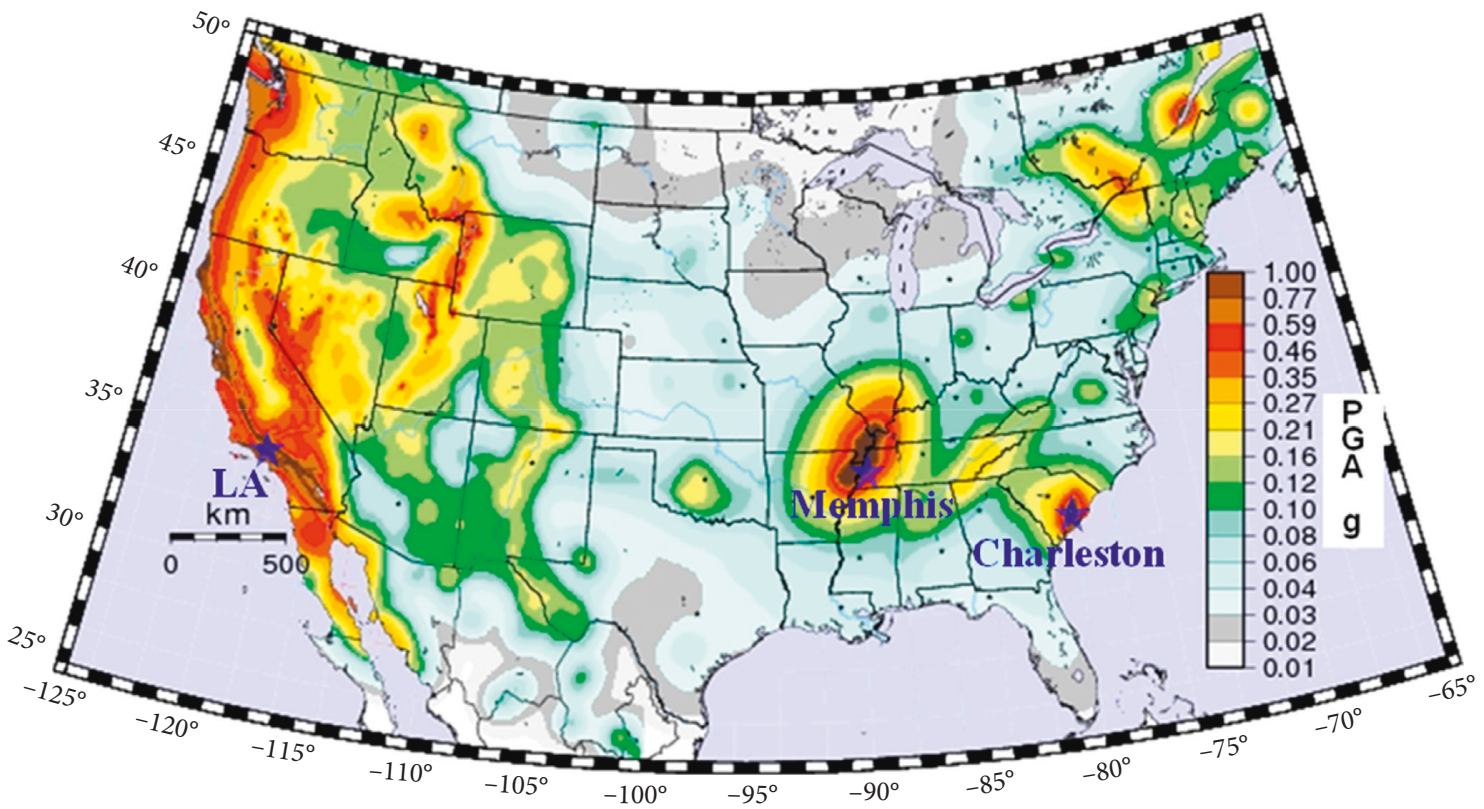

(b)

FIGURE 14: Seismic hazard maps for the US [58]: (a) 10\% probability of exceedance in 50 years map of PGA; (b) $2 \%$ probability of exceedance in 50 years map of PGA.

Finally, Figure 16 shows the risk (i.e., annual CDF) of case 1 and case 2 in Los Angeles, Memphis, and Charleston. These are estimated using the convolution of the mean seismic fragility curve of each case and the log-log linear seismic hazard curves of Figure 15. The following are the observed findings:

(i) In case 1 (strength failure mode), the risk is reduced by 69.5 and 8.6 times for Los Angeles, 15.8 and 4.1 times for Memphis, and 9.6 and 3.2 times for Charleston due to the SSI effect. (ii) However, in case 2 (displacement failure mode), the risk is increased by 60.3 and 2.5 times for Los Angeles, by 13.3 and 1.7 times for Memphis, and by 8.0 and 1.6 times for Charleston because of the SSI effect.

(iii) Regardless of the sites considered, a significant deviation in the risk results is observed to arise from the SSI effect.

The risk spread is particularly noticeable in Los Angeles on the western site of the US, which indicates that this site is 


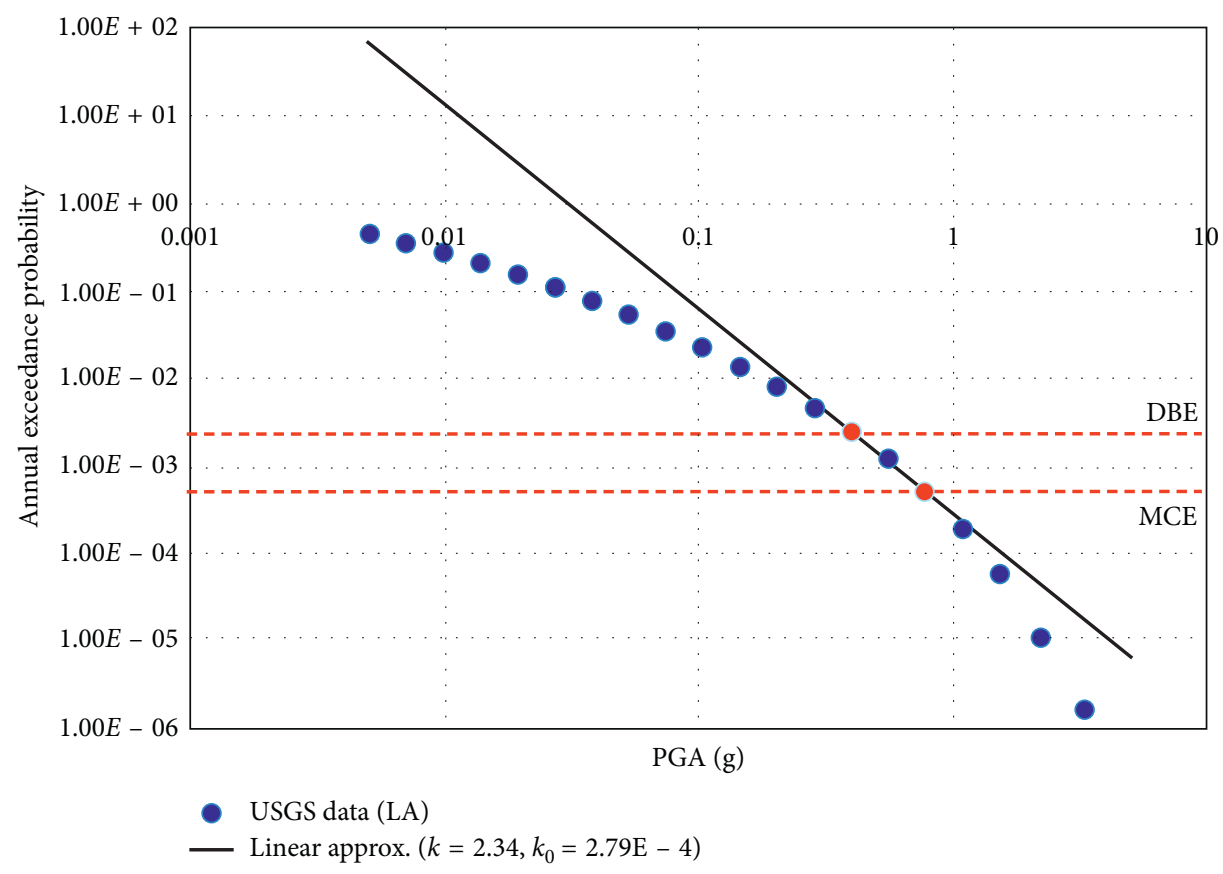

(a)

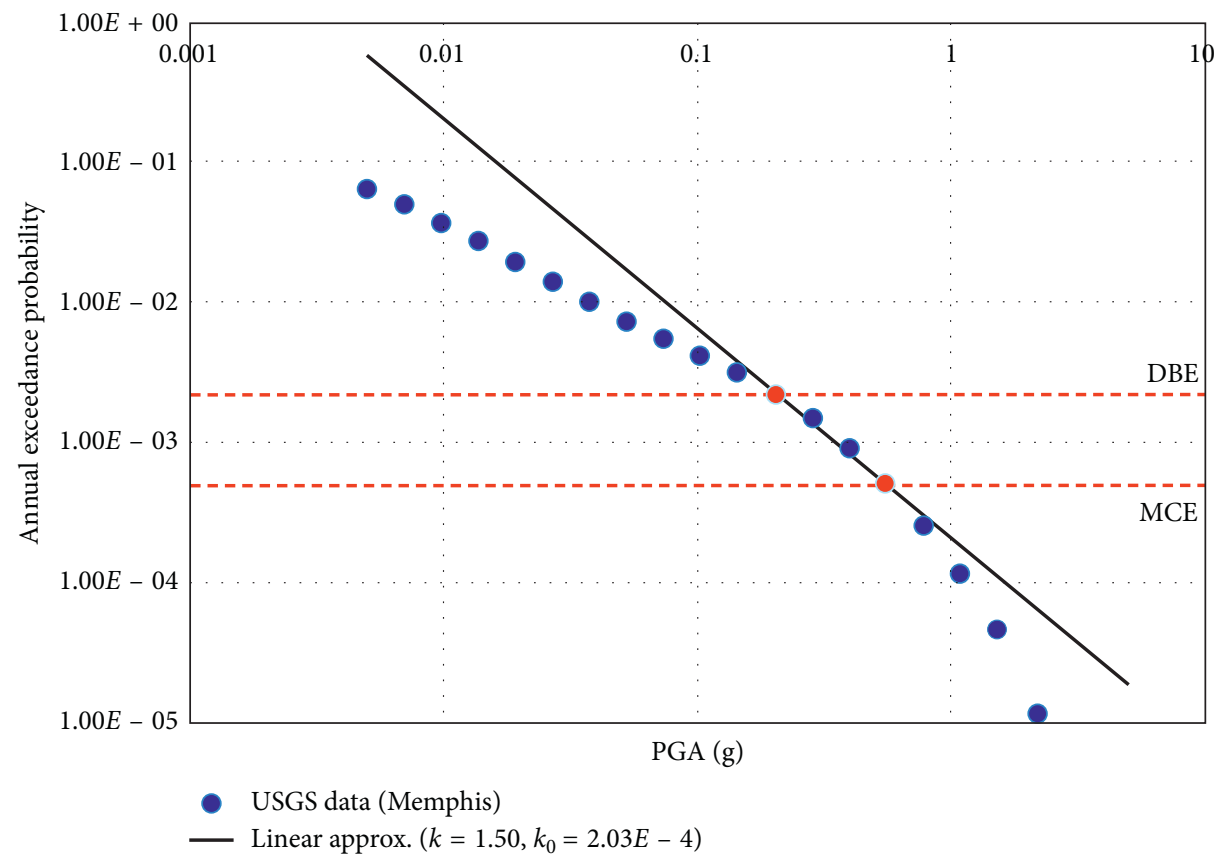

(b)

FIgURE 15: Continued. 


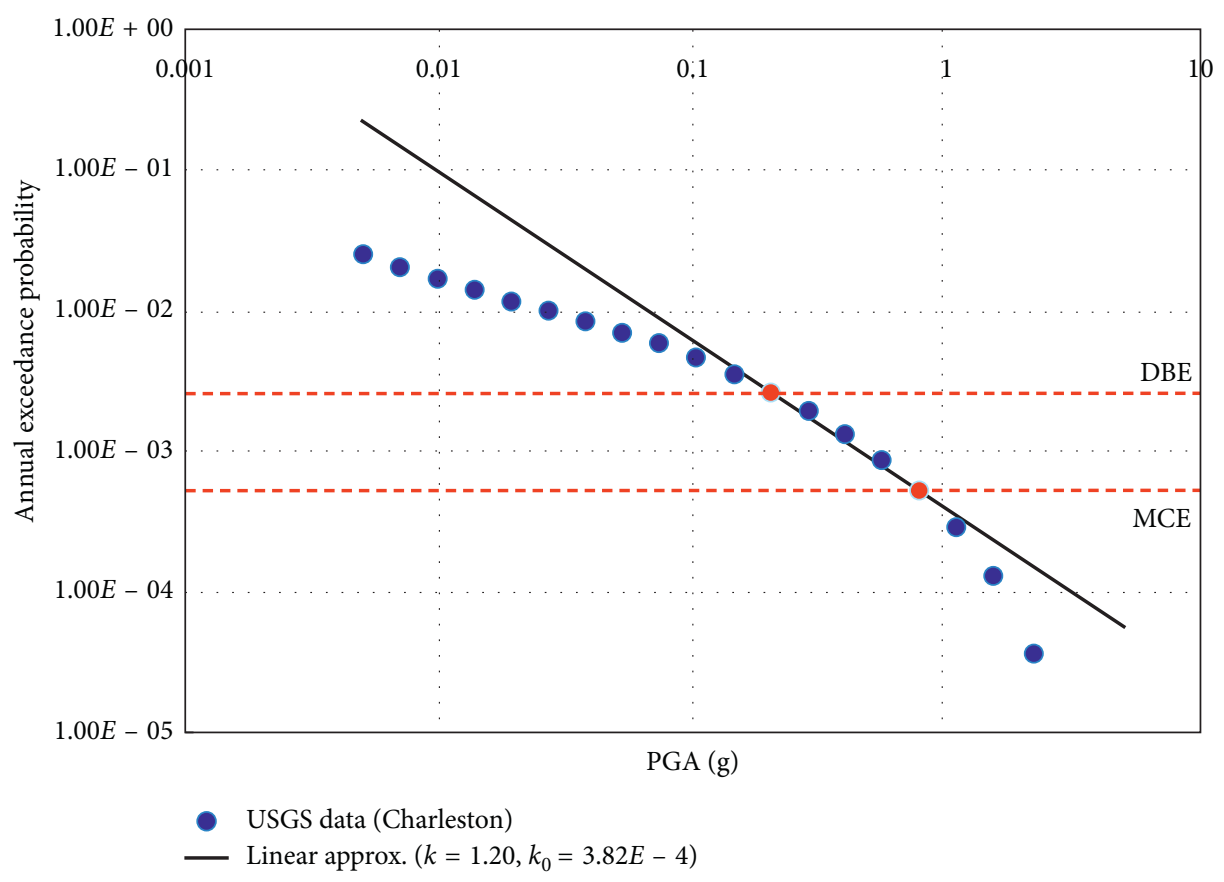

(c)

Figure 15: Seismic hazard curves for (a) Los Angeles, (b) Memphis, and (c) Charleston.

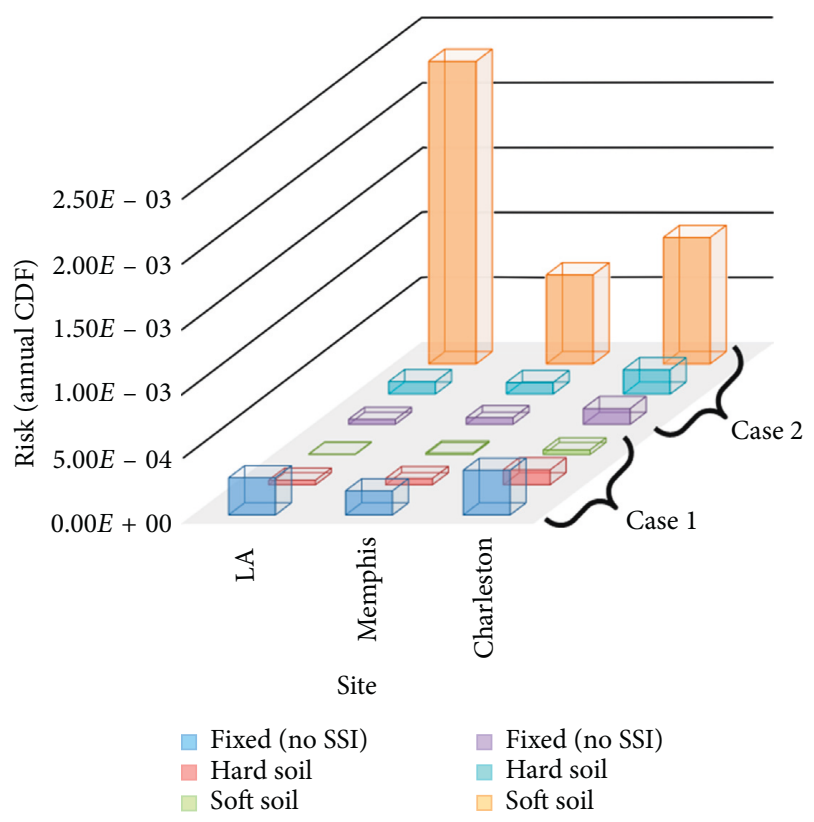

FIGURE 16: Comparison of the annual core damage frequencies.

the most risk-sensitive area out of the three sites. The reason for this risk result is attributable to the fact that the slope $(k)$ of the seismic hazard curve of Los Angeles is rather steep compared to those of Memphis and Charleston. Finally, it is noteworthy that consideration of the SSI has a complete conflicting effect on the risk depending on the failure modes of interest. If the SSI is associated with the strength failure mode of case 1, it has the positive effect on the risk. On the contrary, if the SSI is related to the displacement failure mode of case 2, it has the negative effect on the total risk. This observation shows a similar context represented in Figures 11 and 12. Such findings ultimately support the core argument of this study.

\section{Summary and Conclusion}

This study explores the SSI effect on the overall risk of a PWR containment building structure with respect to two failure modes: strength and displacement. Such an exploration is based on the current SPRA framework which integrates seismic hazard and fragility information. For the fragility analysis purpose, the factor of the safety method and the MLE-based statistical approach are employed. The seismic responses of the containment structure supported on the three soil conditions: fixed, hard, and soft, are obtained by using site response analyses and inelastic time-history analyses, and such results are then utilized for basic information in the fragility quantification. The discrete seismic hazard information in the site of interest and the log-log linear approximation are utilized for the conservative risk assessment. Finally, the seismic fragility and risk results in the three different soil conditions are compared for each failure mode.

In conclusion, the main findings of this study are as follows.

(i) The soft soil amplifies the spectral accelerations over all frequencies, and the amplification is prominent in $1-2 \mathrm{~Hz}$ and $3-5 \mathrm{~Hz}$. However, the hard soil does not make the site responses amplified relatively. 
(ii) The displacement responses at no SSI and hard soil conditions approximately have a similar pattern at the top of the containment structure. But the result on the soft soil is almost 5 to 10 times higher in all PGA ranges than the hard soil.

(iii) The consideration of SSI shows a complete conflicting effect on the seismic fragility and risk depending on the two failure modes. This has a positive effect regarding the strength failure mode, but this brings a negative effect regarding the displacement failure mode.

(iv) The risk fluctuation width is particularly noticeable in the site having a considerable change in seismic hazard information (i.e., steep slope in the log-log seismic hazard curve) such as Los Angeles on the western site of the US.

All these results are because the soft soil condition acts like a seismic isolator at the base of the containment structure. Such a feature induces the excessive displacement at the top of the structure but causes the structure to perform rigid body motion and, accordingly, reduces internal deformation in the structure. These particular findings have a clear limitation because this study is based on a certain containment structure model, three general soil conditions, and two limited failure modes. Thus, the future work in this direction needs to include various failure modes and investigate the pros and cons of the SSI effect associated with these failure modes in diverse conditions.

\section{Data Availability}

The data that support the findings of this study are available from the corresponding author upon reasonable request.

\section{Conflicts of Interest}

The authors declare that there are no conflicts of interest regarding the publication of this paper.

\section{Acknowledgments}

This work was supported by a National Research Foundation of Korea (NRF) Grant funded by the Korean government (Ministry of Science and ICT) (NRF-2017R1C1B1002855).

\section{References}

[1] ESNRG, Stress Tests Specifications, European Nuclear Safety Regulatory Group-European Commission, European Council, Europa building, Brussels, 2011.

[2] USNRC, Japan Lessons-Learned Project Directorate: Guidance on Performing a Seismic Margin Assessment in Response to the March 2012 Request for Information Letter, JLD-ISG-2012-04, Revision 0, 2012a, 2012.

[3] KINS, Stress Test Performance Specification, Korea Institute of Nuclear Safety, Daejeon, Republic of Korea, 2013.

[4] R. J. Budnitz, P. J. Amico, C. A. Cornell et al., "Approach to the quantification of seismic margins in nuclear power plants," TNUREG/CR-4334, UCID-20444, Lawrence Livermore National Lab., Livermore, CA, USA, 1985.
[5] EPRI, "A methodology for assessment of nuclear power plant seismic margin," NP-6041-SLR1, Electric Power Research Institute, Palo Alto, CA, USA, 1991.

[6] USNRC, "Reactor safety study," WASH-1400, NUREG 73/ 041, US Nuclear Regulatory Commission, Rockville, MD, USA, 1975.

[7] USNRC, "PRA procedure guide. A guide to the performance of probabilistic risk assessments for nuclear power plants," NUREG/CR-2300, US Nuclear Regulatory Commission, Rockville, MD, USA, 1983.

[8] IAEA, Procedures for Conducting Probabilistic Safety Assessments of Nuclear Power Plants (Level 1), Safety Series No. 50-P4, International Atomic Energy Agency, Vienna, Austria, 1992.

[9] EPRI, "Methodology for developing seismic fragilities," TR103959, Electric Power Research Institute, Palo Alto, CA, USA, 1994.

[10] USNRC, "Procedural and submittal guidance for the individual plant examination of external events (IPEEE) for severe accident vulnerabilities," NUREG-1407, US Nuclear Regulatory Commission, Rockville, MD, USA, 1991.

[11] S. Kwag, J. Oh, J-.M. Lee, and J.-S. Ryu, "Bayesian-based seismic margin assessment approach: application to research reactor," Earthquakes and Structures, vol. 12, no. 6, pp. 653663, 2017.

[12] P. J. Stewart, G. L. Fenves, and R. B. Seed, "Seismic soilstructure interaction in buildings. I: analytical methods," Journal of Geotechnical and Geoenvironmental Engineering, vol. 125, no. 1, pp. 26-37, 1999.

[13] G. Mylonakis and G. Gazetas, "Seismic soil-structure interaction: beneficial or detrimental?," Journal of Earthquake Engineering, vol. 4, no. 3, pp. 277-301, 2000.

[14] USNRC, Standard Review Plan (SRP) Sec. 3.7.2: Seismic Design Parameters, NUREG0800 Revision 4, 2012.

[15] J. Coleman, "Demonstration of nonlinear seismic soil structure interaction and applicability to new system fragility seismic curves," INL/EXT-14-33222, Idaho National Lab (INL), Idaho Falls, ID, USA, 2014.

[16] F. Behnamfar and M. Banizadeh, "Effects of soil-structure interaction on distribution of seismic vulnerability in RC structures," Soil Dynamics and Earthquake Engineering, vol. 80, pp. 73-86, 2016.

[17] F. Mirzaie, M. Mahsuli, and M. A. Ghannad, "Probabilistic analysis of soil-structure interaction effects on the seismic performance of structures," Earthquake Engineering and Structural Dynamics, vol. 46, no. 4, pp. 641-660, 2017.

[18] Z. Zhou and X. Wei, "Seismic soil-structure interaction analysis of isolated nuclear power plants in frequency domain," Shock and Vibration, vol. 2016, Article ID 6127895, 15 pages, 2016.

[19] S. El-Bahey, Y. Alzeni, and K. Oikonomou, "Effect of soilstructure interaction on the seismic fragility of a nuclear reactor building," Journal of Nuclear Engineering and Radiation Science, vol. 4, no. 2, p. 020912, 2018.

[20] D. M. Ghiocel, P. R. Wilson, G. G. Thomas, and J. D. Stevenson, "Seismic response and fragility evaluation for an Eastern US NPP including soil-structure interaction effects," Reliability Engineering and System Safety, vol. 62, no. 3, pp. 197-214, 1998.

[21] M. Vermaut, P. Monette, P. Shah, and R. D. Campbell, "Methodology and results of the seismic probabilistic safety assessment of Krško nuclear power plant," Nuclear engineering and design, vol. 182, no. 1, pp. 59-72, 1998.

[22] S. H. Eem, H. J. Jung, M. K. Kim, and I. K. Choi, "Seismic fragility evaluation of isolated NPP containment structure 
considering soil-structure interaction effect," Journal of the Earthquake Engineering Society of Korea, vol. 17, no. 2, pp. 53-59, 2013.

[23] S. M. Hoseyni, F. Yousefpour, A. A. Araei, K. Karimi, and S. M. Hoseyni, "Effects of soil-structure interaction on fragility and seismic risk; a case study of power plant containment," Journal of Loss Prevention in the Process Industries, vol. 32, pp. 276-285, 2014.

[24] R. K. McGuire, "Probabilistic seismic hazard analysis and design earthquakes: closing the loop," Bulletin of the Seismological Society of America, vol. 85, no. 5, pp. 1275-1284, 1995.

[25] C. A. Cornell, F. Jalayer, R. O. Hamburger, and D. A. Foutch, "Probabilistic basis for 2000 SAC Federal Emergency Management Agency steel moment frame guidelines," Journal of Structural Engineering, vol. 128, no. 4, pp. 526-533, 2002.

[26] B. A. Bradley, R. P. Dhakal, M. Cubrinovski, J. B. Mander, and G. A. MacRae, "Improved seismic hazard model with application to probabilistic seismic demand analysis," Earthquake Engineering and Structural Dynamics, vol. 36, no. 14, pp. 2211-25, 2007.

[27] R. P. Kennedy, C. A. Cornell, R. D. Campbell, S. Kaplan, and H. F. Perla, "Probabilistic seismic safety study of an existing nuclear power plant," Nuclear Engineering and Design, vol. 59, no. 2, pp. 315-338, 1980.

[28] R. P. Kennedy and M. K. Ravindra, "Seismic fragilities for nuclear power plant risk studies," Nuclear Engineering and Design, vol. 79, no. 1, pp. 47-68, 1984.

[29] S. Kwag, J. M. Lee, J. Oh, and J. S. Ryu, "Development of system design and seismic performance evaluation for reactor pool working platform of a research reactor," Nuclear Engineering and Design, vol. 266, pp. 199-213, 2014.

[30] J. Oh, S. Kwag, and J. M. Lee, "A new design concept and seismic margin assessment for a spent fuel storage system," Nuclear Engineering and Design, vol. 326, pp. 150-161, 2018.

[31] M. Shinozuka, M. Q. Feng, J. Lee, and T. Naganuma, "Statistical analysis of fragility curves," Journal of engineering mechanics, vol. 126, no. 12, pp. 1224-1231, 2000.

[32] J. W. Baker and C. A. Cornell, "Vector-valued ground motion intensity measures for probabilistic seismic demand analysis," Report No. 150, Blume Earthquake Engineering Center, Stanford, CA, USA, 2005.

[33] J. Rice, Mathematical Statistics and Data Analysis, Nelson Education, Toronto, QC, Canada, 2006.

[34] A. Mosleh and G. Apostolakis, "The assessment of probability distributions from expert opinions with an application to seismic fragility curves," Risk Analysis, vol. 6, no. 4, pp. 447-461, 1986.

[35] A. Singhal and A. S. Kiremidjian, "Bayesian updating of fragilities with application to RC frames," Journal of structural Engineering, vol. 124, no. 8, pp. 922-929, 1998.

[36] M. Sasani and A. D. Kiureghian, "Seismic fragility of RC structural walls: displacement approach," Journal of Structural Engineering, vol. 127, no. 2, pp. 219-228, 2001.

[37] P. Gardoni, A. Der Kiureghian, and K. M. Mosalam, "Probabilistic capacity models and fragility estimates for reinforced concrete columns based on experimental observations," Journal of Engineering Mechanics, vol. 128, no. 10, pp. 1024-1038, 2002.

[38] D. Straub and A. Der Kiureghian, "Improved seismic fragility modeling from empirical data," Structural Safety, vol. 30, no. 4, pp. 320-336, 2008.

[39] P. S. Koutsourelakis, "Assessing structural vulnerability against earthquakes using multi-dimensional fragility surfaces: a Bayesian framework," Probabilistic Engineering $\mathrm{Me}$ chanics, vol. 25, no. 1, pp. 49-60, 2010.
[40] S. Kwag and A. Gupta, "Bayesian network technique in probabilistic risk assessment for multiple hazards," in Proceedings of 24th International Conference on Nuclear Engineering (ICONE 24), Charlotte, NC, USA, 2016.

[41] S. Kwag and A. Gupta, "Probabilistic risk assessment framework for structural systems under multiple hazards using Bayesian statistics," Nuclear Engineering and Design, vol. 315, no. 4, pp. 20-34, 2017.

[42] S. Kwag, A. Gupta, and N. Dinh, "Probabilistic risk assessment based model validation method using Bayesian network," Reliability Engineering and System Safety, vol. 169, pp. 380-393, 2018.

[43] S. Kwag and A. Gupta, "Computationally efficient fragility assessment using equivalent elastic limit state and Bayesian updating," Computers and Structures, 2018, In press.

[44] H. Hwang, B. Ellingwood, M. Shinozuka, and M. Reich, "Probability-based design criteria for nuclear plant structures," Journal of structural engineering, vol. 113, no. 5, pp. 925-942, 1987.

[45] S. Kwag and S-. Y. Ok, "Robust design of seismic isolation system using constrained multi-objective optimization technique," KSCE Journal of Civil Engineering, vol. 17, no. 5, pp. 1051-1063, 2013.

[46] P. D. Smith, R. G. Dong, D. L. Bernreuter et al., "Seismic safety margins research program. Phase I, final report-overview," NUREG/CR-2015-Vol. 1, UCRL-53021-Vol. 1, Lawrence Livermore National Lab., Livermore, CA, USA, 1987.

[47] B. S. Ju and A. Gupta, "Seismic fragility of threaded Tee-joint connections in piping systems," International Journal of Pressure Vessels and Piping, vol. 132, pp. 106-118, 2015.

[48] Y. J. Lee and D. S. Moon, "A new methodology of the development of seismic fragility curves," Smart Structures and Systems, vol. 14, no. 5, pp. 847-867, 2014.

[49] S. L. Kramer, Geotechnical Earthquake Engineering, Prentice Hall, Inc., Upper Saddle River, NJ, USA, 1996.

[50] P. B. Schnabel, "SHAKE: a computer program for earthquake response analysis of horizontally layered sites," EERC Report, University of California, Berkeley, CA, USA, 1972.

[51] MIDAS IT, MIDAS GEN Structural Analysis Program Version 795, MIDAS IT, Navi Mumbai, Maharashtra, 2016.

[52] J. S. Ryu, C. G. Seo, J. M. Kim, and C. B. Yun, "Seismic response analysis of soil-structure interactive system using a coupled three-dimensional FE-IE method," Nuclear Engineering and Design, vol. 240, no. 8, pp. 1949-1966, 2010.

[53] Y. J. Park and C. H. Hofmayer, "Technical guidelines for aseismic design of nuclear power plants," NUREG/CR-6241, Nuclear Regulatory Commission, Rockville, MD, USA, 1994.

[54] Combustion Engineering, System 80+ Standard Design, US DOE, New York, NY, USA, 1990.

[55] US Nuclear Regulatory Commission, A Performance-Based Approach to Define the Site-Specific Earthquake Ground Motion, Regulatory Guide Version 1.208, US Nuclear Regulatory Commission, Rockville, MD, USA, 2007.

[56] US Nuclear Regulatory Commission, Design Response Spectra for Seismic Design of Nuclear Power Plants, Regulatory Guide Version 1.60, US Nuclear Regulatory Commission, Rockville, MD, USA, 2014.

[57] USNRC, Risk Assessment of Operational Events in External Events, Vol. 2, US Nuclear Regulatory Commission, Rockville, MD, USA, 2008.

[58] M. D. Petersen, M. P. Moschetti, P. M. Powers et al., Documentation for the 2008 update of the United States national seismic hazard maps (No. 2008-1128), US Geological Survey, Reston, VA, USA, 2008. 


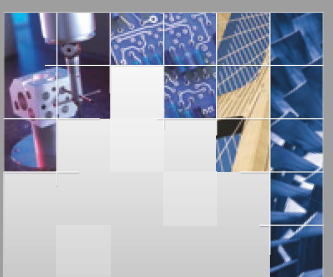

\section{Enfincering}
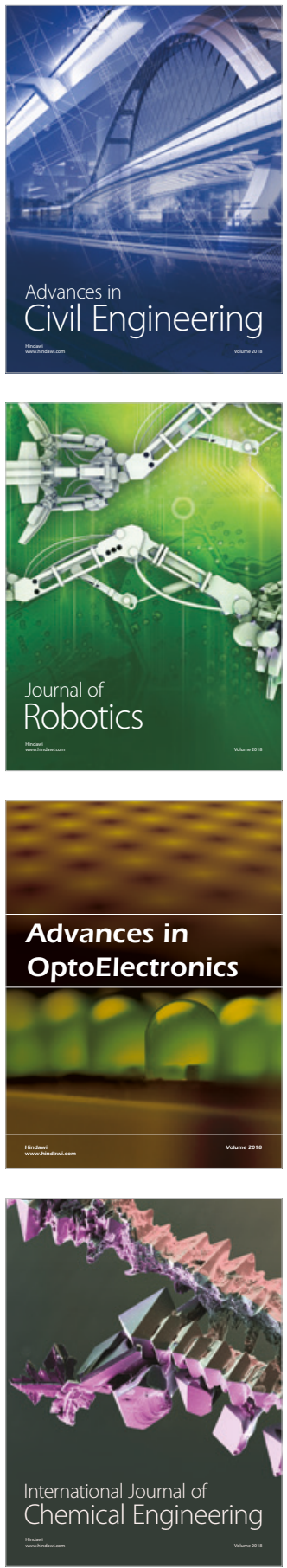

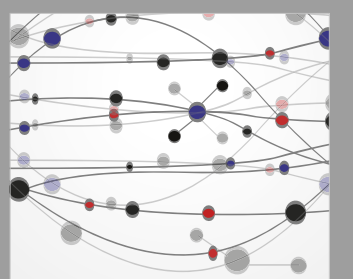

\section{Rotating \\ Machinery}

The Scientific World Journal

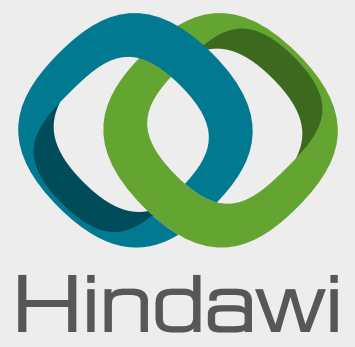

Submit your manuscripts at

www.hindawi.com
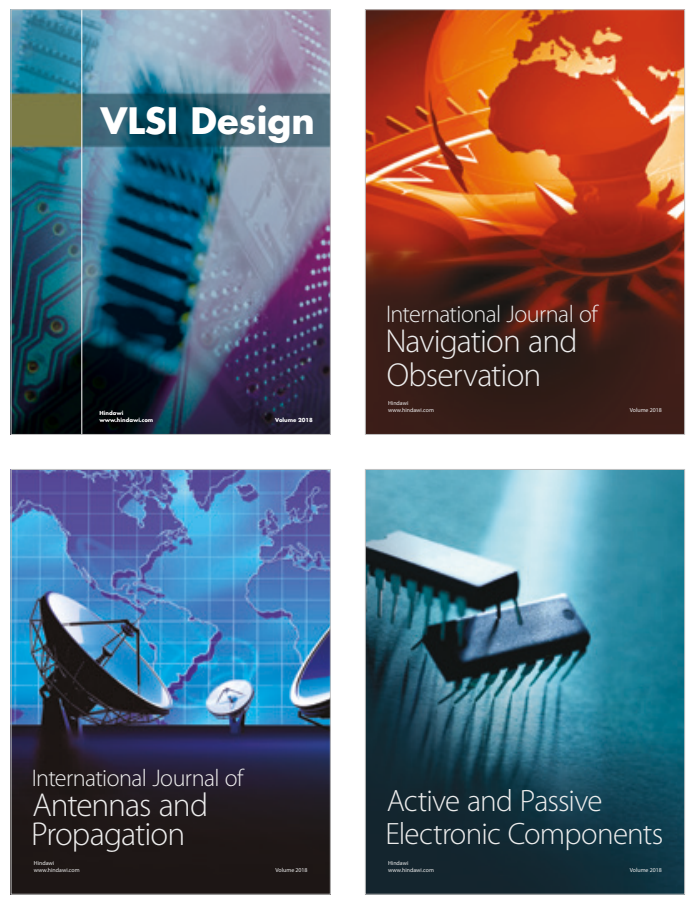
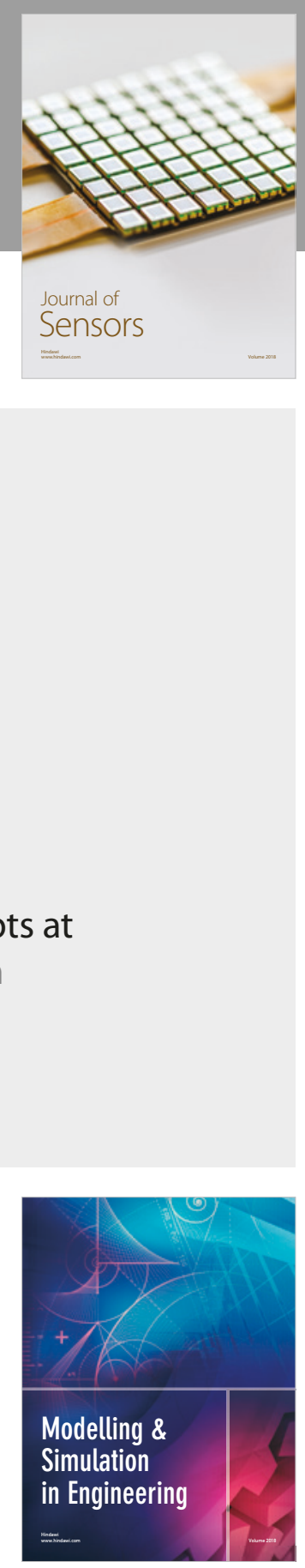

\section{Advances \\ Multimedia}
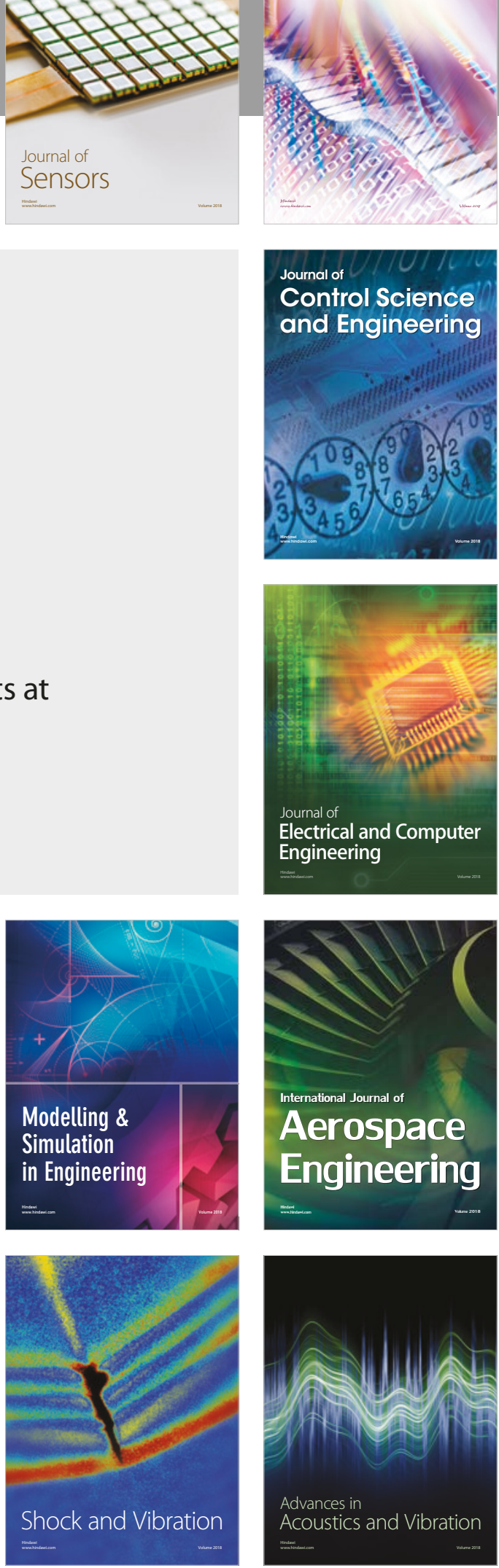